\title{
Potential Liquid-Organic Hydrogen Carrier (LOHC) Systems: A Review on Recent Progress
}

\author{
Purna Chandra Rao and Minyoung Yoon *(1) \\ Department of Chemistry \& Green-Nano Materials Research Center, Kyungpook National University, \\ Daegu 41566, Korea; purna@knu.ac.kr \\ * Correspondence: myyoon@knu.ac.kr; Tel.: +82-53-950-6347
}

Received: 22 October 2020; Accepted: 17 November 2020; Published: 19 November 2020

\begin{abstract}
The depletion of fossil fuels and rising global warming challenges encourage to find safe and viable energy storage and delivery technologies. Hydrogen is a clean, efficient energy carrier in various mobile fuel-cell applications and owned no adverse effects on the environment and human health. However, hydrogen storage is considered a bottleneck problem for the progress of the hydrogen economy. Liquid-organic hydrogen carriers (LOHCs) are organic substances in liquid or semi-solid states that store hydrogen by catalytic hydrogenation and dehydrogenation processes over multiple cycles and may support a future hydrogen economy. Remarkably, hydrogen storage in LOHC systems has attracted dramatically more attention than conventional storage systems, such as high-pressure compression, liquefaction, and absorption/adsorption techniques. Potential LOHC media must provide fully reversible hydrogen storage via catalytic processes, thermal stability, low melting points, favorable hydrogenation thermodynamics and kinetics, large-scale availability, and compatibility with current fuel energy infrastructure to practically employ these molecules in various applications. In this review, we present various considerable aspects for the development of ideal LOHC systems. We highlight the recent progress of LOHC candidates and their catalytic approach, as well as briefly discuss the theoretical insights for understanding the reaction mechanism.
\end{abstract}

Keywords: liquid-organic hydrogen carrier (LOHC); hydrogen storage; hydrogenation; dehydrogenation; catalyst

\section{Introduction}

Energy is crucial for development of the modern world. So far, most energy requirements are fulfilled by fossil-based fuels. Indeed, rapid industrialization and advanced technologies affect the fuel economy, and in other direction, the vast consumption of fossil energies causes anthropogenic global warming, which negatively impacts the environment and human health. Moreover, our giant usage engenders the depletion of fossil-based resources and faces severe shortage in the near future. In fact, renewable energy sources, such as solar and wind, have attracted enormous attention [1]. However, these resources are not yet stable and fluctuate depending on the season. Alternatively, batteries reinforce global electric transportation [2]; however, this technology presents limitations, such as slow charging rates, scarcity of $\mathrm{Li}$ and Co with large-scale utility, and may be costly [3]. Hence, alternative energy sources must be sought to conquer the current energy demands. In this context, hydrogen is a clean and efficient energy carrier and can be employed as a carbon-emission free fuel for a variety of appliances, such as fuel-cell vehicles, stationary and portable electronics, etc. [4,5].

Hydrogen $\left(\mathrm{H}_{2}\right)$ is the lightest element in the periodic table; it is a colorless, odorless, and tasteless gas with a low volumetric density of $0.08988 \mathrm{~g} / \mathrm{L}$ at 101,325 Pa [6]. The idea of using hydrogen as an energy source and carrier was presented several decades ago. In 1971, Jones postulated that the use of liquid hydrogen must be seriously considered as a logical replacement for hydrocarbon fuels in 
the 21st century [7]. Substantially, Winsche et al. [8], Momirlan et al. [9], and Bockris [10] have been highlighted the hydrogen roles and its benefits in the future hydrogen fuel economy. Though hydrogen is anticipated to be a clean and efficient energy carrier, production is highly challenging. In this respect, there are different varieties of primary energy sources, as well as various efficient technologies that have been developed for the production of hydrogen. Mostly, non-renewable resources such as natural gas and coal are displaying similar participation in $\mathrm{H}_{2}$ production. Nevertheless, renewable and sustainable energy (RSE) sources have shown significant attention for long-term production of clean hydrogen, for example, the splitting of water into hydrogen $\left(\mathrm{H}_{2}\right)$ and oxygen $\left(\mathrm{O}_{2}\right)$ by electrolysis process [11] and the generating electricity by wind energy, which can be utilized in water electrolysis. The ubiquitous RSE source, solar energy, also produces hydrogen by employing sunlight as an energy source in water splitting process. Furthermore, biomass energy can generate hydrogen by biological and thermochemical processes [12,13]. Despite extensive research toward the production of clean $\mathrm{H}_{2}$, safe and cost-effective storage and transportation of hydrogen is a major task in the development of a hydrogen economy. To date, many physical and chemical hydrogen storage techniques have been extensively investigated. In physical storage methods, high pressure compression in cylinders (up to $7 \times 10^{4} \mathrm{kPa}$ ) and liquefaction of hydrogen are commercially used. However, hydrogen compression in capable cylinders should withstand high pressures $\left((2-7) \times 10^{4} \mathrm{kPa}\right)$ and required expensive composite materials (aluminum, steel, or thermoplastic-lined carbon fibers) for making these storage tanks [14]. Then, liquifying hydrogen $\left(-253^{\circ} \mathrm{C}\right)$ in cryogenic tanks also requires expensive, multi-storage cooling protocols [15]. In contrast, chemical storage techniques comprised of metal hydrides and their alloys [16,17] (e.g., $\mathrm{MgH}_{2}, \mathrm{LaNi}_{5} \mathrm{H}_{6}, \mathrm{NaAlH}_{4}$ ), store hydrogen via chemisorption and physisorption of hydrogen by porous materials [18-20] (e.g., activated carbon, graphene, carbon nanotubes, and metal-organic frameworks), in which these are more favorable storage methods. Nevertheless, metal hydrides and associated complexes face severe issues, such as lower gravimetric hydrogen capacities ( $<5.5 \mathrm{wt} \%$; In 2010, the Department of Energy (DOE) target hydrogen capacity was $6 \mathrm{wt} \%$ for entire systems including tanks, regulators, valves, etc., and in 2017, the DOE designated targets of $5.5 \mathrm{wt} \%, 40 \mathrm{~g} \mathrm{~L}^{-1}$, for mobile applications [21].), limited reversibility at optimal pressure-temperature regions, and instability of storage materials. Furthermore, physisorption of solid materials requires extremely low temperatures $\left(-196{ }^{\circ} \mathrm{C}\right)$. Given this, research efforts have drawn attention toward the development of alternative hydrogen storage compounds, known as liquid-organic hydrogen carriers (LOHCs).

By definition, LOHCs are organic compounds which exist as liquids or low melting point solids under ambient storage conditions. Indeed, LOHC systems are potentially safe and relatively cheap storage materials. These systems can have a pair of hydrogen-rich $(\mathrm{H} 2+)$ and hydrogen-lean $(\mathrm{H} 2-)$ molecules. In this system, hydrogen is stored by $\mathrm{H} 2-$ molecules through catalytic hydrogenation (exothermic), and hydrogen is released by catalytic dehydrogenation (endothermic) reactions of $\mathrm{H} 2+$ molecules at optimal temperature and pressure conditions (Scheme 1). Notably, the high gravimetric and volumetric storage of hydrogen in small organic molecules have shown significant promise due to their numerous advantages, such as easy and clean energy storage without any concept-induced leakages, compatibility with present transport and refueling infrastructures, as well as operation under ambient conditions (pressure or temperature). To date, several efficient LOHC compounds have been developed. However, research efforts toward their development and practical usage is still in infancy. Thus, based on reported literature [22-24], a LOHC system should meet the following characteristic properties in order to employ as good candidate for practical applications. 

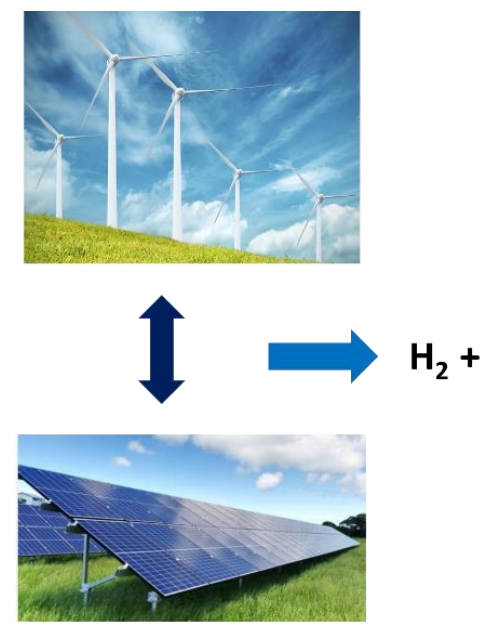

\section{Renewable energy}

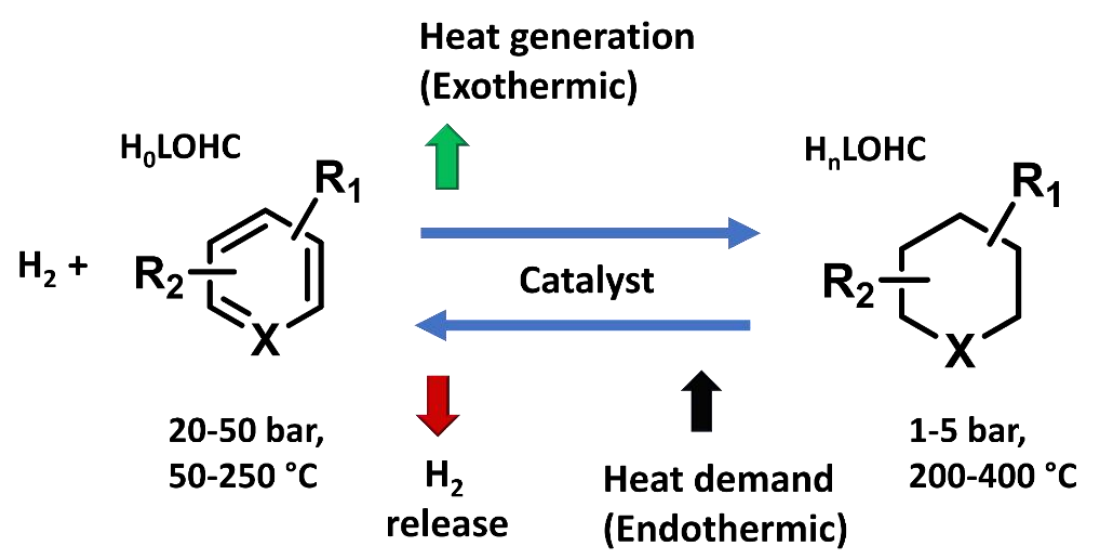

Heat generation

Scheme 1. Schematic representation of the LOHC concept.

- It should be non-toxic and safe, with an acceptable eco-toxicology profile during transportation and usage.

- To avoid the need for solid-based fuel infrastructure and external addition of solvents, LOHC systems should have low melting points with favorable values $<-30{ }^{\circ} \mathrm{C}$.

- The boiling point of the LOHC system should be high $\left(>300{ }^{\circ} \mathrm{C}\right)$ to simplify the purification of hydrogen and require low dynamic viscosity for easy pumping.

- Reasonably high volumetric $\left(>56 \mathrm{~kg} / \mathrm{m}^{3}\right)$ and gravimetric storage capacities $(>6 \mathrm{wt} \%)$ are required.

- To attain the stability of LOHC molecules and achieve low dehydrogenation temperatures $\left(<200{ }^{\circ} \mathrm{C}\right.$ at $100 \mathrm{kPa} \mathrm{H}_{2}$ pressure), the desired hydrogen binding enthalpy should be in the range of $40-70 \mathrm{~kJ} / \mathrm{mol} \mathrm{H}_{2}$, based on Wild et al. [25] and $42-54 \mathrm{~kJ} / \mathrm{mol} \mathrm{H}_{2}$ per Cooper et al. [26].

- The system should be able to liberate sufficiently pure $\mathrm{H}_{2}$ while producing very selective hydrogenated and dehydrogenated products over long-life cycles, as well as avoiding alternative decomposition pathways.

- It should be compatible with existing fuel infrastructure and have low production costs.

Therefore, the above-mentioned characteristic properties pave the way for novel discoveries toward the development of efficient LOHC candidates in the near future. However, none of the known LOHCs, such as naphthalene, N-ethyl carbazole (NEC), etc., have achieved these properties to the full extent. This review focuses on a brief description of LOHC characteristic properties from a thermodynamic point of view. Additionally, a recent progress of well-known and newly developed LOHC candidates with associated catalytic systems are highlighted, followed by a brief discussion of theoretical efforts toward the development of efficient LOHC systems.

\section{Brief History of LOHCs}

Research studies toward hydrogen storage in LOHCs via hydrogenation/dehydrogenation processes first took place in the early 1980s [27]. Based on the (de)hydrogenation processes, the most predominant task was pointed out as toluene/methylcyclohexane (MCH) system [28]. Following the $\mathrm{MCH}$ system research, numerous LOHC concepts have been assessed based on hydrogenation and dehydrogenation criteria for hydrogen storage. In the early 2000s, the basic concept of a cyclohexane/benzene LOHC system was investigated by Japanese researchers and they examined similar systems in more detail $[29,30]$. Notably, NEC was proposed as a LOHC candidate by Pez et al. in 2005 [31], and then in-depth research of this carrier material has been continued by various groups [32-34]. The latter, different research groups have also shown significant interest 
in alternative azaborine carrier materials [35-37]. In 2008, Crabtree suggested that N-containing heterocyclics are more advantageous LOHC materials, in terms of ease of $\mathrm{H}_{2}$ release, safe storage, low vapor pressure, better biodegradability, and simple heat management [38]. Muller et al. proposed that nitrogen-containing aromatic compounds are well-suited for better hydrogen storage based on thermodynamic evaluation [39], emphasized by their enthalpy changes during hydrogenation. Based on the LOHC concept, a mile stone was reached by the Chiyoda Corporation (Japan; Scheme 2) [40]. This company completed a pilot-plant facility for large-scale hydrogenation and dehydrogenation of LOHC materials in 2018. Additionally, numerous potential LOHC candidates were proposed and exploited in practical applications such as decentralized energy storage network [41], combined heat and power (CHP) systems [42]. Eypasch et al. demonstrated theoretical assumption of energy supply based on LOHC for industrial production plants [43]. Very recently, Niermann et al. indicated that LOHCs are technologically efficient and economically promising safe transportation and storage materials [44].

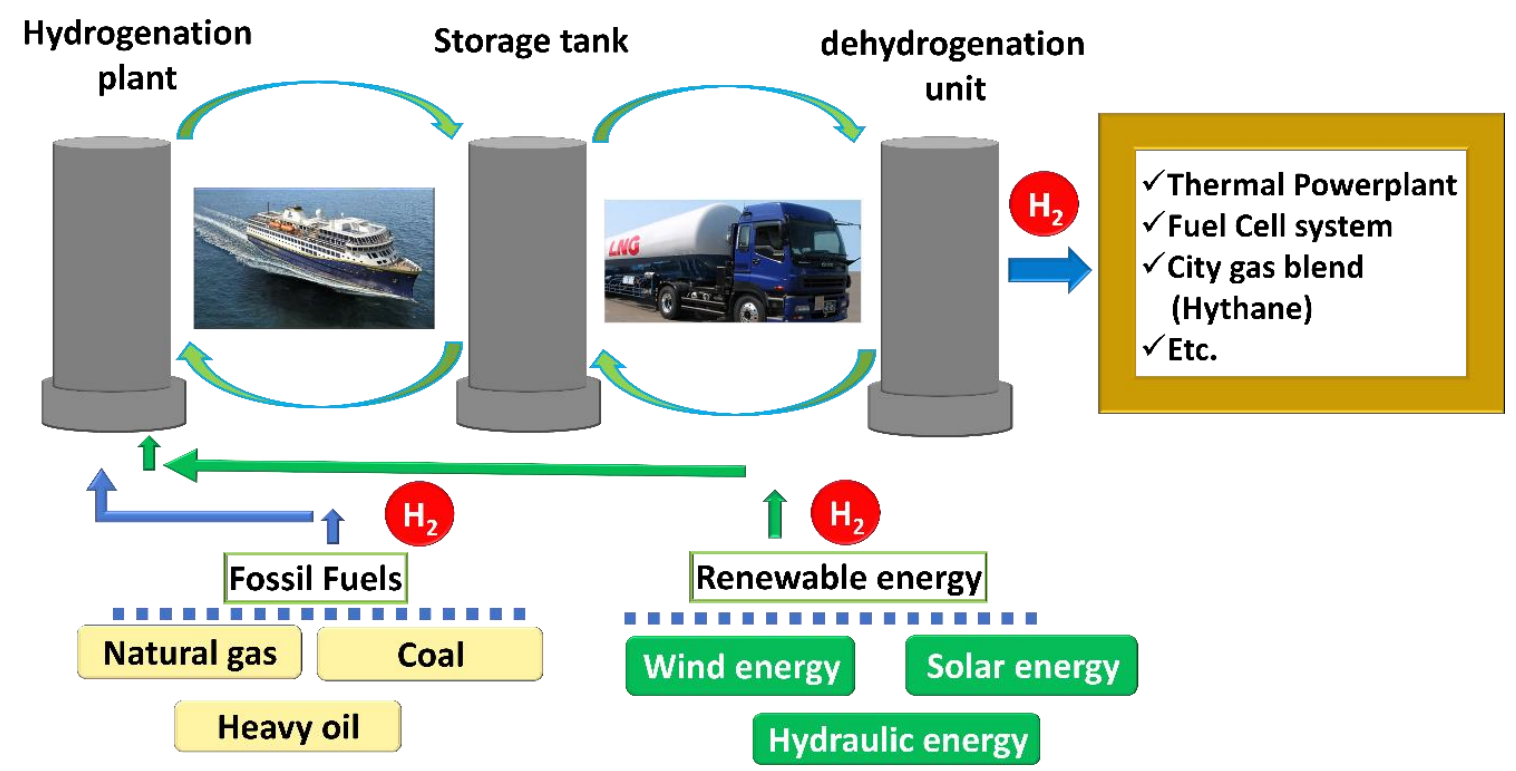

Scheme 2. The demonstration plan for large-scale hydrogen storage and transportation, as proposed by Chiyoda Corporation (Japan).

In this context, a wide range of potential LOHCs have been proposed in the literature and are highlighted based on the thermodynamic properties [38,39]. Efficient LOHCs have been proposed, and important insights into catalytic processes have been gleaned from theoretical approaches such as density functional theory (DFT) and ab initio-DFT calculations [22,45]. Further, contributions regarding fundamental catalytic aspects for hydrogenation and dehydrogenation of LOHCs have also been discussed [46].

\section{Critical Issues in Developing LOHC Media}

According to reported literature, we briefly discuss a few important LOHC characteristic properties and key aspects of LOHC catalytic systems as well as numerous other factors more generally for practical implementation of LOHCs.

\subsection{Hydrogenation/Dehydrogenation}

Usually, reversible hydrogenation and dehydrogenation at ambient temperature conditions is the primary requirement for hydrogen storage LOHC candidates. Thermodynamically, the feasibility of these reactions is strongly influenced by the thermodynamic reaction enthalpies. In particular, aromatic hydrogenation reactions are highly exothermic and thermodynamically favorable (e.g., aromatic benzene ring enthalpy is $\Delta^{\mathrm{R}} \mathrm{h}=-68.73 \mathrm{~kJ} / \mathrm{mol} \mathrm{H}_{2}$, but the released energy not typically used. On the other hand, dehydrogenation is endothermic and requires high heat demand which is in the range 
of $64-69 \mathrm{~kJ} / \mathrm{mol} \mathrm{H}_{2}$, and as a result, this reaction is unfavorable both kinetically and thermodynamically (e.g., cyclohexane/benzene and $\mathrm{MCH} /$ toluene pairs) [47,48]. In contrast, liquid hydrogen carriers require low heat management though it needs an active catalyst in the dehydrogenation process. Considering these thermodynamic difficulties, Pez and coworkers for the first time suggested in their patent, the use of N-heterocyclics (e.g., NEC) decreases endothermicity and enhance hydrogen release as compared with alicyclics at relatively lower temperatures [31]. In addition, Crabtree and coworkers' systematic computational studies on structural factors generalized the substitution of nitrogen atoms in five- and six-membered rings how judiciously achieving the lower $\mathrm{H}_{2}$ release temperatures [49]. Based on Muller et al.'s contribution, the facile reaction enthalpy for an ideal $\mathrm{LOHC}$ candidate is about $40 \mathrm{~kJ} / \mathrm{mol} \mathrm{H}_{2}$, and they suggested nitrogen-substituted aromatic compounds could reach this requirement easily, despite non-aromatic compounds being barely suitable [39]. Hence, these reports encourage the nitrogen-containing compounds are the focus of interest in developing novel LOHC systems.

\subsection{Reaction Catalysts for $\mathrm{LOHC}$}

Another crucial aspect in LOHC development is selection of the proper catalytic system for hydrogenation and dehydrogenation reactions. As discussed in Section 3.1, chemical storage of hydrogen in liquid carriers is attained exothermically during hydrogenation process whereas endothermic liberation of hydrogen is observed during dehydrogenation process, moreover, this endothermicity is a major drawback due to the requirement of high heat demand. Though thermodynamic evaluation is the one of the concerns in designing the LOHCs, an active catalytic system with a high to moderate loading of precious metal catalysts (e.g., $\mathrm{Pd}, \mathrm{Pt}$, $\mathrm{Rh}$, and $\mathrm{Ru})$ can actually achieve acceptable dehydrogenation kinetics at low temperatures $\left(\leq 150^{\circ} \mathrm{C}\right)$. In particular, numerous homogenous catalysts [50-52] have been developed for this purpose; however, the achieved stability, recycling, and practical advantages in large-scale applications have more precisely promoted heterogeneous catalyst systems. Various commercial heterogenous catalysts with different supporting substances (e.g., $\mathrm{Pd} / \mathrm{C}, \mathrm{Pt} / \mathrm{Al}_{2} \mathrm{O}_{3}$, and $\mathrm{Pd}-\mathrm{Pt} / \mathrm{Al}_{2} \mathrm{O}_{3}$ ) have attracted much attention for LOHC technology [46]. However, high catalyst efficiency is the major criteria in which metal loading, appropriate support selection, and structural properties (particle size, porosity, active surface area, etc.) are all important characteristics [53-55]. To this end, development and optimization of efficient catalyst systems obviously requires both experimental and theoretical approaches. Theoretical studies using DFT calculations can provide fundamental insight into catalytic activity and selectivity over different metal surfaces and experimental methods comprised of various spectroscopic techniques (typically X-ray photoelectron spectroscopy (XPS), temperature-programmed desorption (TPD), and infrared reflection absorption spectroscopy (IRAS), etc.) further support the field of LOHC dehydrogenation catalysis $[45,56]$. Combining these complementary approaches, the development of efficient catalytic systems is promising.

\subsection{Features of LOHC Medium}

\subsubsection{Melting and Boiling Points}

In 2017, the US DOE designated an organic hydrogen carrier target gravimetric storage capacity of $5.5 \mathrm{wt} \% \mathrm{H}_{2}$ relative to the storage system including the carrier, tank, and dehydrogenation unit [21]. Predominantly, the carrier materials depend on two major concerns: storage density (typically $7.3 \mathrm{wt} \%$ for naphthalene) and existed temperature range in which the material remains a liquid. Despite the storage density requirement, carrier compounds can have low melting points $\left(<-30{ }^{\circ} \mathrm{C}\right)$ [57]; otherwise need to use of additional solvents to dissolve it which hinders the targeted storage capacity. Usually, larger aromatic compounds, like naphthalene and anthracene have high storage capacities but solidify at room temperature. In this regard, destroying the symmetry by substituting alkyl chains (e.g., cyclohexane melts at $6.5^{\circ} \mathrm{C}$ whereas $\mathrm{MCH}$ melts at $-126.6{ }^{\circ} \mathrm{C}$ ) is an alternative solution [58], though it decreases storage capacity. Besides, the boiling point (b.pt.) of 
carrier molecules should be as high as possible $\left(>300^{\circ} \mathrm{C}\right)$ which can minimize the vapor pressure during dehydrogenation and storage. In this case, larger aromatic compounds (e.g., b.pt. of anthracene is $342{ }^{\circ} \mathrm{C}$ ) are more advantageous than smaller compounds (e.g., toluene b.pt. is $110.6{ }^{\circ} \mathrm{C}$ ), except for the occurrence of their solid phase states. Therefore, these mentioned thermodynamic properties should be helpful in guiding future LOHC development.

\subsubsection{Stability of LOHC Molecules}

The consequent consideration in developing of ideal LOHCs is fall under the stability aspect of LOHC molecules. In LOHC technology, carrier molecule stability is strongly affected by hydrogenation and dehydrogenation temperatures under relevant catalytic medium. In particular, lower temperature conditions can avoid the decomposition pathways, thereby, yielding no side-product formation and allowing for long-term use. On the other hand, suitable catalysts with high activity can minimize the reaction temperatures. For example, carbazole-based derivatives undergo dealkylation which potentially leads to deterioration of LOHC materials at the required dehydrogenation temperatures. In this case, Amende et al. reported that control of particle size and structure-dependent effects of active metal catalysts on well-defined surfaces could benefit for long-term stability [56,59]. Thus, understanding both structural properties and theoretical studies on model catalysts and their activities can facilitate development of future LOHC molecules.

\subsubsection{Toxicity and Biodegradability}

Considering practical applicability, toxicity and biodegradability of LOHC materials must be evaluated. Owing to the increased benefits of LOHC technology, hazard assessment of molecules needs to be examined to minimize negative impacts on human health and the environment. As rated by the Toxicity Potential Indicator (TPI), values cover the range of " 0 " for non-toxic to " 100 " for extremely toxic [60]. Generally, toxicity assessment is more common for dehydrogenation counterparts than hydrogenated molecules [23]. For example, the safety data for the technical dibenzyl toluene mixture (Marlotherm SH; MSH) is described as low risk, and ecotoxicological problems are less than common diesel and are comparatively more favorable than NEC [61]. In addition, biodegradability is another key factor of a LOHC system. In this scenario, nitrogen-containing molecules typically have better biodegradability than alicyclic molecules, as reported by Crabtree [24]. Very recently, Markiewicz et al. reported hazard assessment of quinaldine, three-different alkyl carbazoles, benzene, and toluene based on mutagenicity, cytotoxicity, acute aquatic toxicity and biodegradability of each LOHC system [62]. Therefore, study on toxicity and biodegradability of LOHC molecules are imperative for developing LOHC systems.

In addition, there are several factors such as flashpoint, ignition temperature, density, viscosity, and surface tensions, that need be considered for the development of LOHC systems. Though these properties are not addressed to the full extent in the literature for all LOHC molecules, only few molecules are well-documented due to their utilization in mobile applications $[61,63]$.

\section{Classification of LOHC Media and Catalytic Systems}

In the field of LOHCs, many organic carrier molecules have been reported to date, and several important review articles cover various aspects of this topic $[23,45,46,48,64]$. Herein, we discuss recent research development of hydrogenation and dehydrogenation catalytic systems. Owing to the high heat demand for dehydrogenation, the development of efficient dehydrogenation catalysts has been extensively studied. Based on structural characteristics and utilization purposes, we selected a few promising LOHC systems and categorized them into two types in the following section: (1) homocyclic and (2) heterocyclic compounds. Further, we highlight recent theoretical efforts for a few compounds with respect to development of model dehydrogenation catalysts. Notably, Section 4.1 describes LOHC carrier molecules toluene, naphthalene, and mono benzyl toluene. On the other hand, recent progress on heterocyclic compounds, including indole derivatives, phenazine, and 2-( $n$-methylbenzyl) pyridine, is discussed in 
Section 4.2. Lastly, though NEC-derivatives are incredibly important, we do not cover them in this review because several recent reviews have already explored these particular LOHC systems $[24,65,66]$.

\subsection{Homocyclic Compounds}

Hydrogenation of aromatic LOHC compounds using precious metal catalysts are more familiar than dehydrogenation reactions [23]. Importantly, promising LOHC systems, toluene, naphthalene, and benzyl toluene (Marlotherm LH, BT), which hydrogenate to $\mathrm{MCH}$, decalin, and perhydro-benzyl toluene, respectively, in the presence of active catalysts have been well studied. Thus, we focus on very recent dehydrogenation catalytic systems and their physicochemical properties (Table 1) for practical utilization in LOHC systems.

\subsubsection{MCH Dehydrogenation}

During the early stages of LOHC technology, one of the most recognized LOHC systems was toluene (TOL)/MCH (Figure 1). Toluene is converted into $\mathrm{MCH}$ using various efficient heterogeneous catalysts during hydrogenation. Liquid-phase $\mathrm{MCH}$ can reach a hydrogen storage capacity of $6.2 \mathrm{wt} \%$ (satisfying the DOE target of $5.5 \mathrm{wt} \%$ ) at ambient conditions. Additionally, its liquid state is beneficial for long-distance transportation, and it can be utilized in many applications. Owing to the high heat demand for dehydrogenation $\left(-68.3 \mathrm{~kJ} / \mathrm{mol} \mathrm{H}_{2}\right), \mathrm{MCH}$ requires harsh conditions, thermodynamically [67]. In this context, Sinfelt and coworkers reported Pt-based catalysts, which emerged as the most efficient and selective catalysts for cycloalkane dehydrogenation [68,69]. Though these catalysts are efficient, they deactivate upon adsorption of dehydrogenated products (aromatic hydrocarbons) and require high temperatures $\left(\geq 350^{\circ} \mathrm{C}\right)$, leading to formation of coke and other side-products (dealkylation) [70]. In addition, the low boiling point $\left(100.9^{\circ} \mathrm{C}\right)$ and low flash point $\left(-3^{\circ} \mathrm{C}\right)$ could be problematic for reversibility, selectivity, and practical purposes. Despite these disadvantages, the Japanese company Chiyoda Corporation has been successful in large-scale production of TOL/MCH LOHC system applications [40].
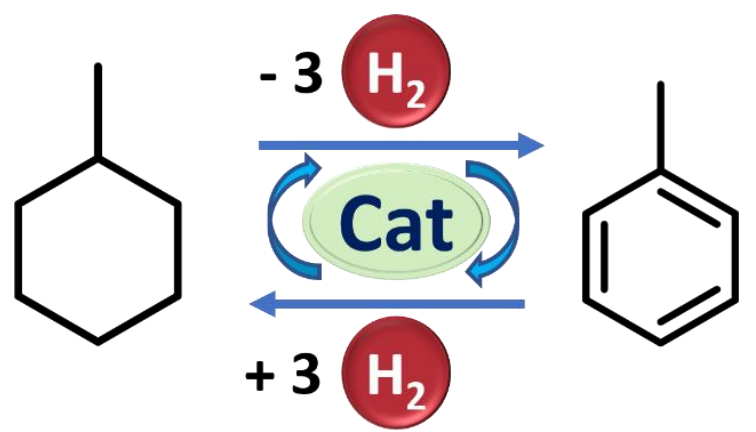

Figure 1. The schematic illustration of methylcyclohexane/toluene LOHC system.

Based on the literature, the two key factors, synergistic effects of bimetallic catalysts (e.g., Pt-Mn, Pt-Sn) and catalytic supports (e.g., $\mathrm{Al}_{2} \mathrm{O}_{3}$ and $\mathrm{SiO}_{2}$ ), play a promising role in improving catalytic performance. To reduce the use of precious metal catalysts (e.g., $\mathrm{Pt}$ ) or improve the efficiency of $\mathrm{MCH}$ dehydrogenation, combination of second metals (typically bimetallic catalysts: Pt-Mn, $\mathrm{Pt}-\mathrm{Sn}$ ) such as Re, Ni, Sn, and Mn, etc., were investigated [71]. The resulting bimetallic catalysts exhibited higher performance than their monometallic counterparts. In the view of catalytic supports, metal oxides (e.g., $\mathrm{ZrO}_{2}, \mathrm{TiO}_{2}$, and $\mathrm{MnO}_{2}$ ) and perovskites $\left(\mathrm{La}_{0.7} \mathrm{Y}_{0.3} \mathrm{NiO}_{3}\right)$ have shown great promise in $\mathrm{MCH}$ dehydrogenation [72]. 
Table 1. Typical examples of potential LOHCs and their physicochemical properties.

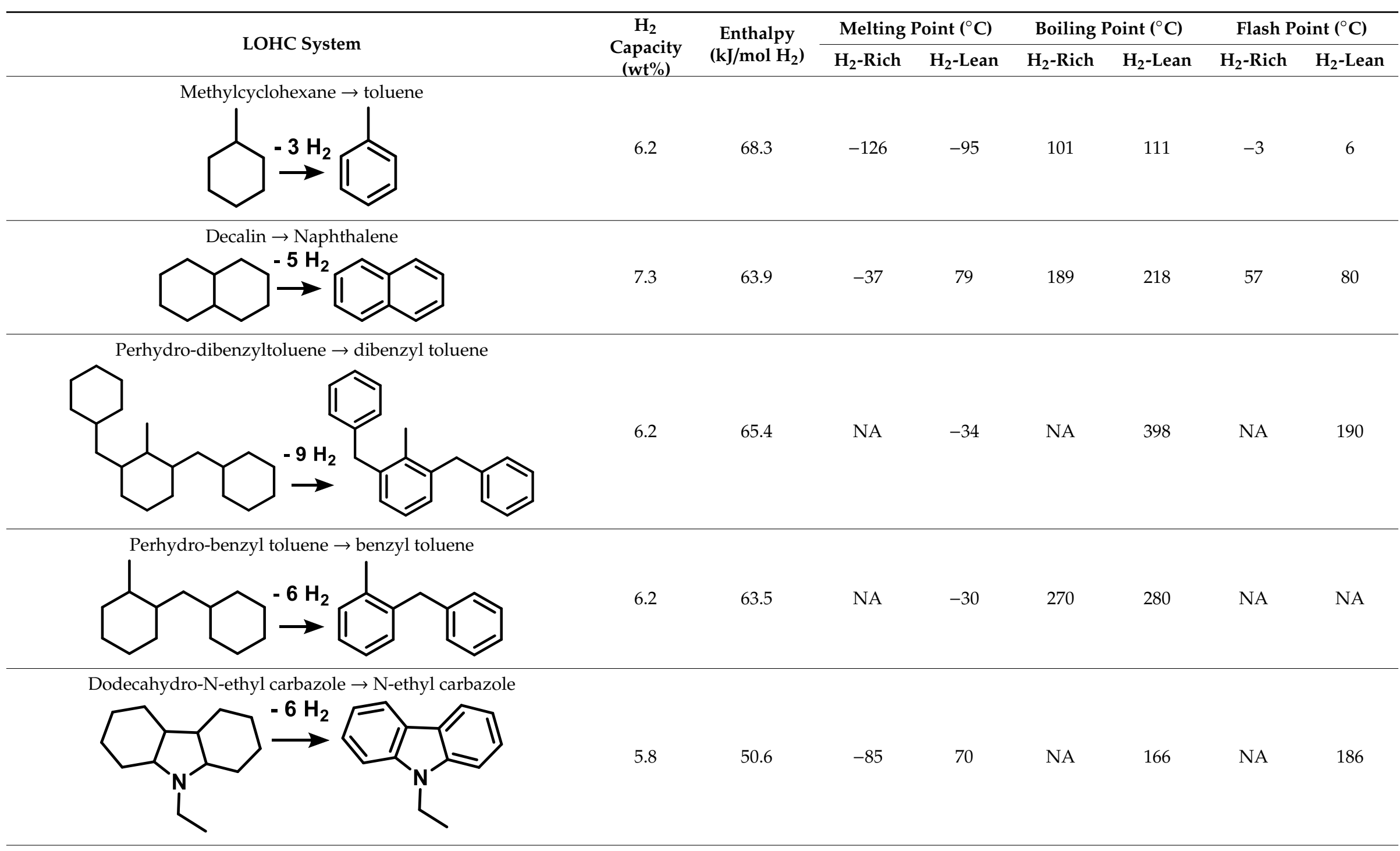


Table 1. Cont

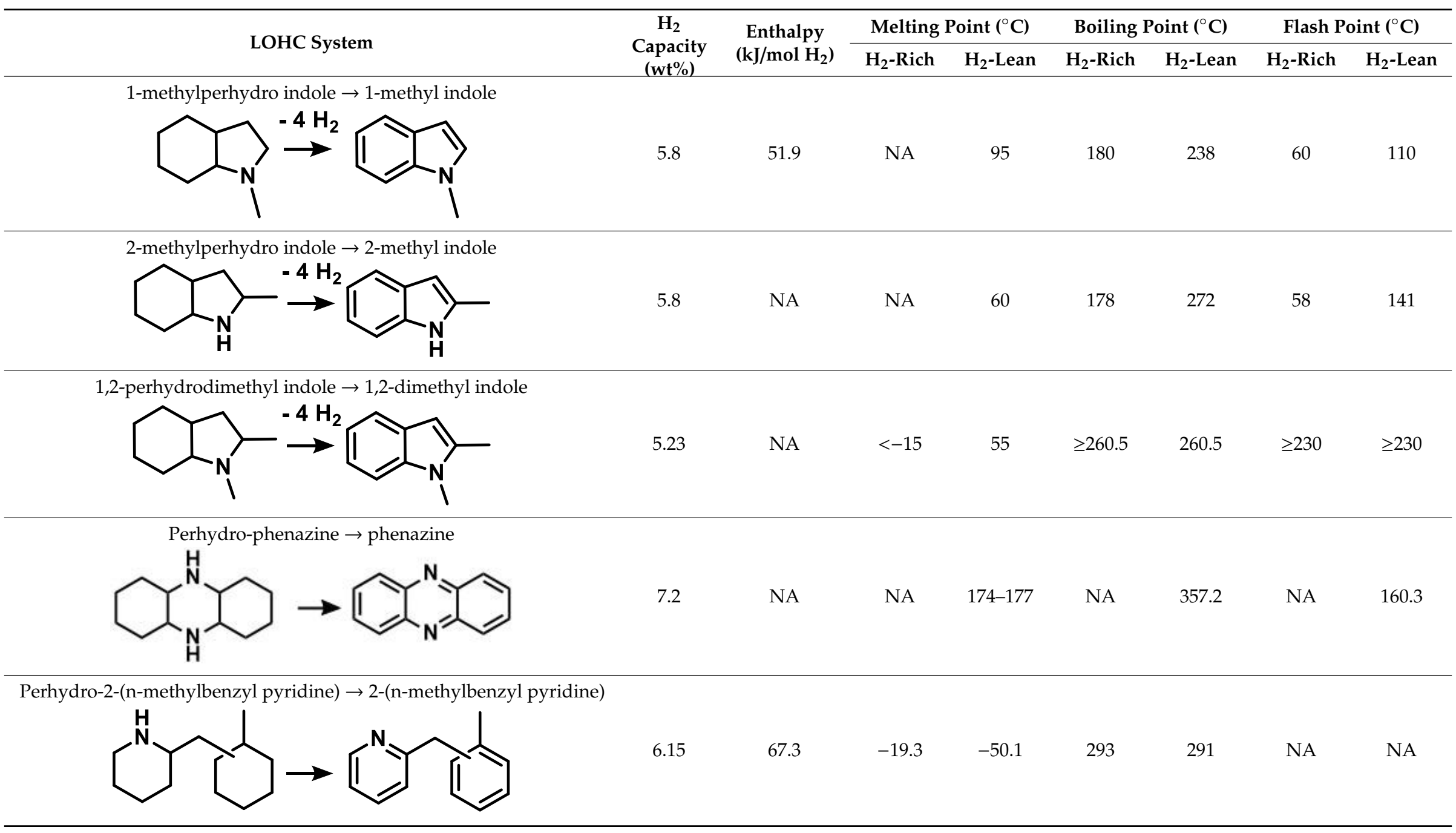


In 2018, Yan et al. reported a novel catalyst, Pt-Sn on Mg-Al metal oxide support showed increase of $\mathrm{MCH}$ dehydrogenation activity and possessed high anti-coking abilities and good stability [73]. Studies on catalytic activity with respect to different $S n$ contents revealed greater performance with $\mathrm{PtSn}-5 / \mathrm{Mg}-\mathrm{Al}-350$ (PtSn-X/Mg-Al-T, where $\mathrm{X}=$ weight percentage of $\mathrm{Sn}$ and $\mathrm{T}=$ reaction temperature, i.e., calcination temperature of catalyst precursors; Figure 2a). Interestingly, compared to monometallic catalysts and the absence of metal oxide supports, the bimetallic catalyst with a Mg-Al-O support, PtSn-5/Mg-Al-O-350, showed better catalytic activity with high $\mathrm{MCH}$ conversion (90.5\%), as well as a $262.1 \mathrm{mmol} / \mathrm{g}_{\mathrm{met}} / \mathrm{min} \mathrm{H}_{2}$ evolution rate at $300{ }^{\circ} \mathrm{C}$. Furthermore, authors declared that enhanced dehydrogenation activity was attributed to interaction between Pt and Sn, the chemical state of Sn, and stabilization of the Sn oxidation state by the Mg support.

(a)

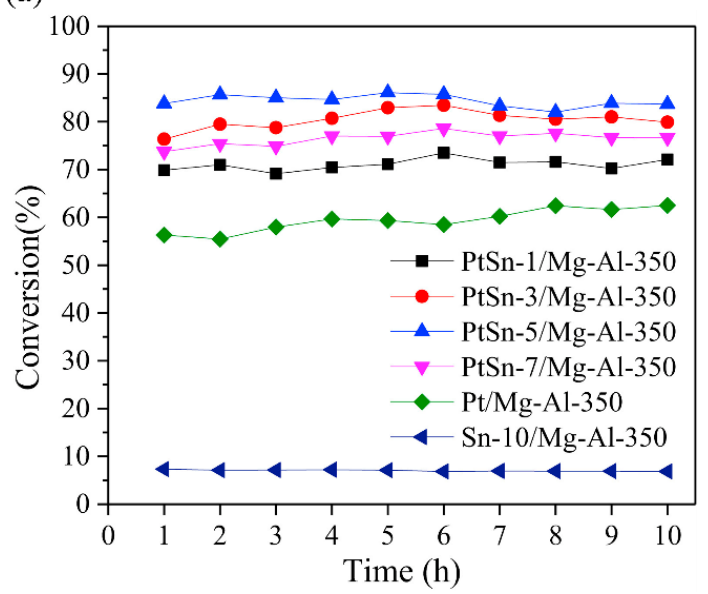

(b)

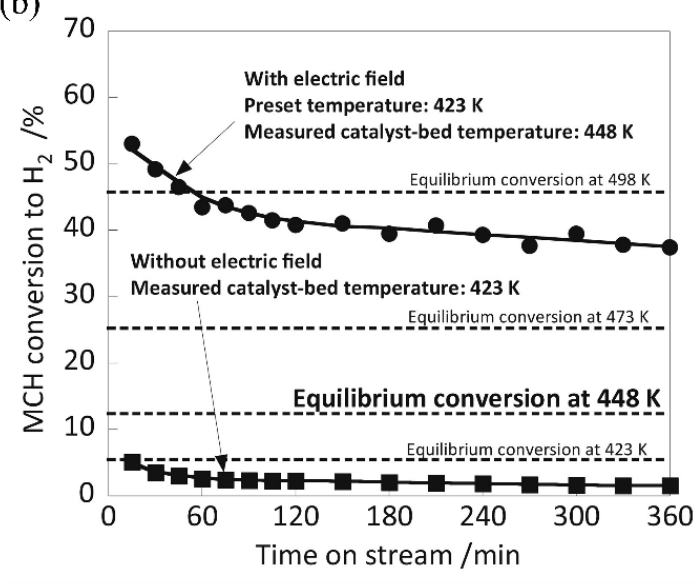

Figure 2. (a) MCH conversion on Pt-Sn supported catalysts with different $\mathrm{Sn}$ contents Reprinted with permission from [73]. (b) Results of catalytic activity tests in the electric field over $\mathrm{Pt} /$ anatase- $\mathrm{TiO}_{2}$ with and without the electric field. Reprinted with permission from [74].

Interestingly, catalytic reactions conducted in an electric field by virtue of surface protonics can improve dehydrogenation selectivity (without coke/methane production) at low temperatures. Very recently, Sekine and coworkers developed a $\mathrm{Pt} /$ anatase- $\mathrm{TiO}_{2}$ catalyst have shown high activity with a $37 \%$ conversion at $448 \mathrm{~K}$ in the presence of an electric field (Figure 2b) [74]. Breakthrough conductivity experiments revealed the role of surface protonics where proton hopping occurs in a $10 \%$ hydrogen atmosphere is improved $\mathrm{MCH}$ dehydrogenation at low temperatures. Moreover, XPS and XANES studies evaluated the states of $\mathrm{Pt}$ active sites $\left(\mathrm{Pt}^{0}, \mathrm{Pt}^{2+}\right.$ to $\left.\mathrm{Pt}^{4+}\right)$ in the $\mathrm{MCH}$ dehydrogenation process. Further, an anatanse- $\mathrm{TiO}_{2}$ support reduced catalyst deactivation by weakening the interaction between $\mathrm{Pt}$ and $\pi$-coordinated toluene.

\subsubsection{Decalin Dehydrogenation}

The next important aromatic hydrocarbon LOHC system is decalin/naphthalene (Figure 3). The hydrogen storage capacity of decalin (DEC) is $7.3 \mathrm{wt} \%$ [75]. Despite having greater storage capacity, the dehydrogenated compound (naphthalene melts at $80^{\circ} \mathrm{C}$ ) is a solid at room temperature. Additionally, the high heat demand for dehydrogenation $\left(66.3 \mathrm{~kJ} / \mathrm{mol} \mathrm{H}_{2}\right)$, irreversibility, and difficulty in transportation engenders the research challenges for practical application of this system. In the literature, several research findings have emphasized the conversion of decalin to naphthalene using dehydrogenation catalysts [76-78]. 


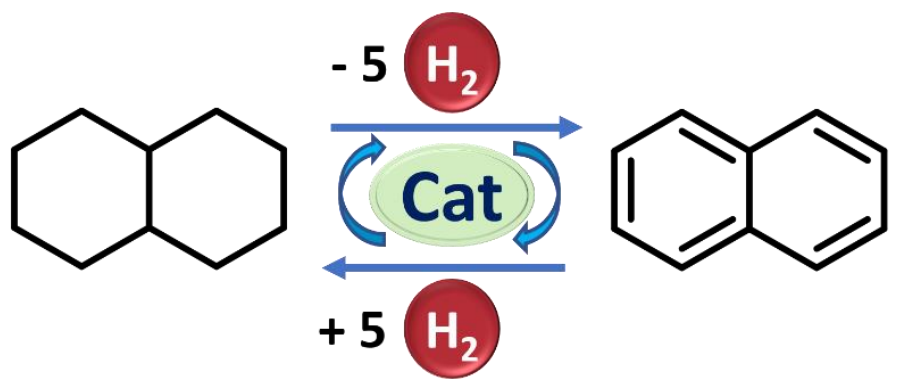

Figure 3. The schematic illustration of decalin/naphthalene LOHC system.

One challenge in combating these difficulties is efficient catalyst selection and optimization of the catalyst/substrate ratio. In this regard, Hodoshima and coworkers developed a novel bimetallic platinum-rhenium composite on granular activated carbon ( $\mathrm{Pt}-\mathrm{Re} / \mathrm{C}$ ) in a "superheated liquid-film-type" state, which demonstrated improved DEC dehydrogenation with both batch-wise and continuous-type reactors [79]. Moreover, the proposed catalytic system required a temperature range of 210 to $280^{\circ} \mathrm{C}$ for both reactors, which is lower than the reported temperature conditions $\left(440^{\circ} \mathrm{C}\right)$. Further, authors supplied hydrogen from decalin by continuous operation ( $50 \mathrm{~kW},>70 \%$ conversion) to fuel-cell vehicles which resulted in fulfill the fuel-cell-vehicle on-board power range (50-80 kW).

Catalyst preparation method plays a key role in improving catalytic performance. Lee et al. reported the effect of $\mathrm{Pt} / \mathrm{C}$ catalyst preparation using various techniques and improved the catalytic activity of decalin dehydrogenation at $210{ }^{\circ} \mathrm{C}$ with a batch-type reactor under reflux conditions $\left(5^{\circ} \mathrm{C}\right)$ [80]. In this report, the four different techniques denoted as impregnation (Im), precipitation (Pr), ion-exchange (Ex), and polyol (Po), were selected for the synthesis of Pt on supported carbon. Afterwards, these catalysts were characterized by XRD, CO-chemisorption, and TEM analyses. Pt/C_Ex and $\mathrm{Pt} / \mathrm{C}_{-} \mathrm{Po}$ showed high catalytic activity in decalin dehydrogenation which was attributed to the $\mathrm{Pt}$ particle size $(5.8 \mathrm{~nm}$ in Pt/C_Ex and $8.1 \mathrm{~nm}$ in Pt/C_Po compared to $21.0 \mathrm{~nm}$ for Pt/C_Im and $11.4 \mathrm{~nm}$ for $\mathrm{Pt} / \mathrm{C} \_\mathrm{Pr}$ ) and excellent dispersion of Pt on the supported carbon. Regarding total hydrogen evolution, the prepared catalyst performances over an hour were as follows: Pt/C_Po $\left(344.4 \mathrm{mmol} \mathrm{H}_{2} / \mathrm{g}_{\mathrm{Pt}}\right)>$

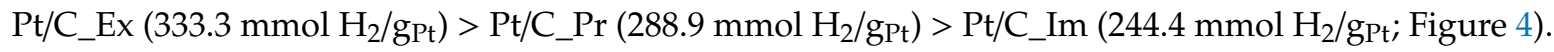

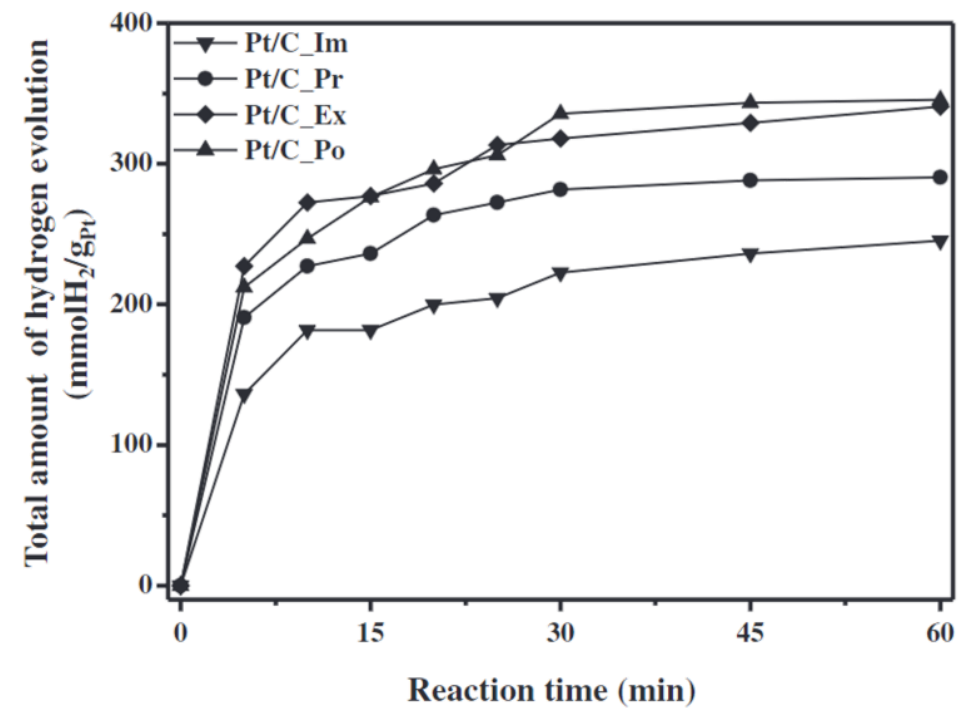

Figure 4. Catalytic performance of carbon-supported platinum catalysts (Pt/C_Im, Pt/C_Pr, Pt/C_Ex, and $\mathrm{Pt} / \mathrm{C} \_$Po) over time on stream in decalin dehydrogenation. Reprinted with permission from [80].

Though precious metal catalysts have been given significant attention, the selection of support materials is another important feature in decalin dehydrogenation to avoid hydrogenolysis and 
cracking products. Very recently, Pimerzin and coworkers compared various supports, mesoporous silicas SBA-15, MCM-48, silica $\left(\mathrm{SiO}_{2}\right)$, and alumina $\left(\mathrm{Al}_{2} \mathrm{O}_{3}\right)$, using $\mathrm{Pt}$ as a metal precursor for decalin dehydrogenation [81]. The low acidity of silica and mesoporous silicas, compared to the commonly used alumina, motivated development of these catalyst systems. Interestingly, Pt/MCM-48 (86\%) and $\mathrm{Pt} / \mathrm{SBA}-15$ (75\%) exhibited relatively high decalin conversion compared with $\mathrm{Pt} / \mathrm{SiO}_{2}(59 \%)$ and $\mathrm{Pt} / \mathrm{Al}_{2} \mathrm{O}_{3}$ (57\%) under 0.5 MPa of pressure, a LHSV (liquid hourly space velocity) of $60 \mathrm{~h}^{-1}$, hydrogen feed stock of $500 \mathrm{nl} / \mathrm{l}$, and $325^{\circ} \mathrm{C}$. In addition, Pt/MCM-48 attained a maximum hydrogen release of $5.7 \mathrm{wt} \%$ at $335^{\circ} \mathrm{C}$ and a LHSV of $20 \mathrm{~h}^{-1}$. The obtained catalytic activity was responsible for the morphology and chemical-physical state properties of Pt catalyst on the supported surfaces.

\subsubsection{Benzyl Toluene Dehydrogenation}

Among the aromatic hydrocarbons, another promising LOHC system is perhydro-benzyl toluene (H12-BT)/benzyl toluene (H0-BT), which stores a hydrogen capacity of $6.2 \mathrm{wt} \%$ (Figure 5). H12-BT is commercially available as heat transfer oil, and the physicochemical properties of this system are more favorable for LOHCs [61]. Moreover, dehydrogenation of H12-BT requires comparatively less heat demand per mole of $\mathrm{H}_{2}\left(63.5 \mathrm{~kJ} / \mathrm{mol} \mathrm{H}_{2}\right)$ than H18-DBT $\left(65.4 \mathrm{~kJ} / \mathrm{mol} \mathrm{H}_{2}\right)$, but its low boiling point $\left(270{ }^{\circ} \mathrm{C}\right)$ compared to $\mathrm{H} 18$-DBT $\left(370{ }^{\circ} \mathrm{C}\right)$ limits the liquid-phase dehydrogenation temperature $[63,82]$. For this reason, most research review articles highlight the perhydro-dibenzyl toluene (H18-DBT)/dibenzyl toluene (H0-DBT) LOHC system due to its reasonable hydrogen storage density $(6.2 \mathrm{wt} \%)$, good technical availability, and compatibility with current fuel infrastructures. However, H12-BT possess the following facile advantages making this LOHC system more attractive in winter (low temperature) energy storage applications:

- faster hydrogen release of H12-BT compared to H18-DBT using $\mathrm{Pt} / \mathrm{Al}_{2} \mathrm{O}_{3}$ catalyst at $270{ }^{\circ} \mathrm{C}$

- formation of structurally less complex intermediates (H6-BT is the only observed intermediate) during hydrogenation/dehydrogenation processes [83], and

- $\quad$ low viscosity of H12-BT (3.94 cP for H0-BT and $6.97 \mathrm{cP}$ for H12-BT) compared to H18-DBT (49 cP for H0-DBT and $389 \mathrm{cP}$ for H18-DBT) at $20^{\circ} \mathrm{C}$.

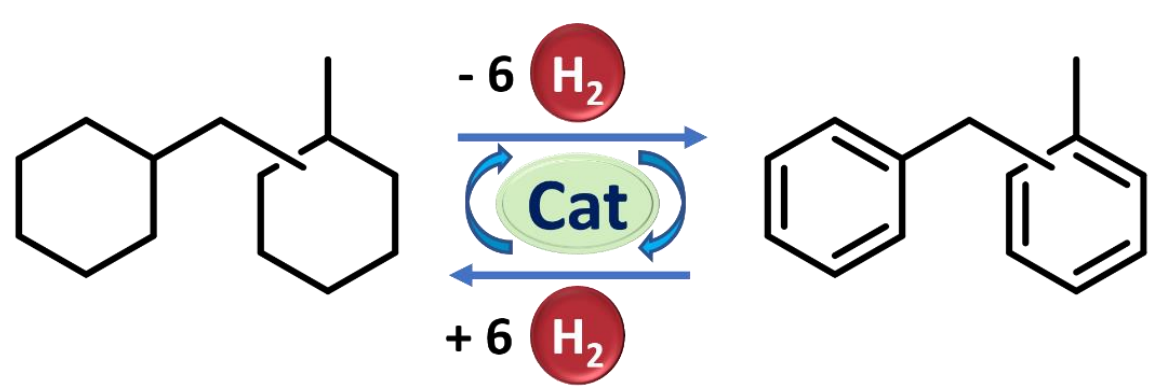

Figure 5. The schematic illustration of perhydro-benzyl toluene/benzyl toluene LOHC system.

The significant release of hydrogen and physicochemical properties of H12-BT at ambient conditions prompt its utilization in low temperature storage applications. Wasserscheid and coworkers proposed mixing of H12-BT with H18-DBT for reducing viscosity as well as enhance hydrogen release productivity as compared to their pure DBT counterparts [82]. Authors mentioned that a $20 \mathrm{wt} \%$ addition of H12-BT to H18-DBT reduced viscosity by $79 \%$ at $10{ }^{\circ} \mathrm{C}$. The dehydrogenation of $\mathrm{H} 12 / \mathrm{H} 18$ mixtures at $260^{\circ} \mathrm{C}$ using Pt on $\mathrm{Al}_{2} \mathrm{O}_{3}$ support increased hydrogen release by $12-16 \%$ compared to pure H18-DBT. The proposed reaction mechanism pathway for the dehydrogenation process is shown in Figure 6. Finally, this multicomponent LOHC system enhances future research developments toward practical application. 


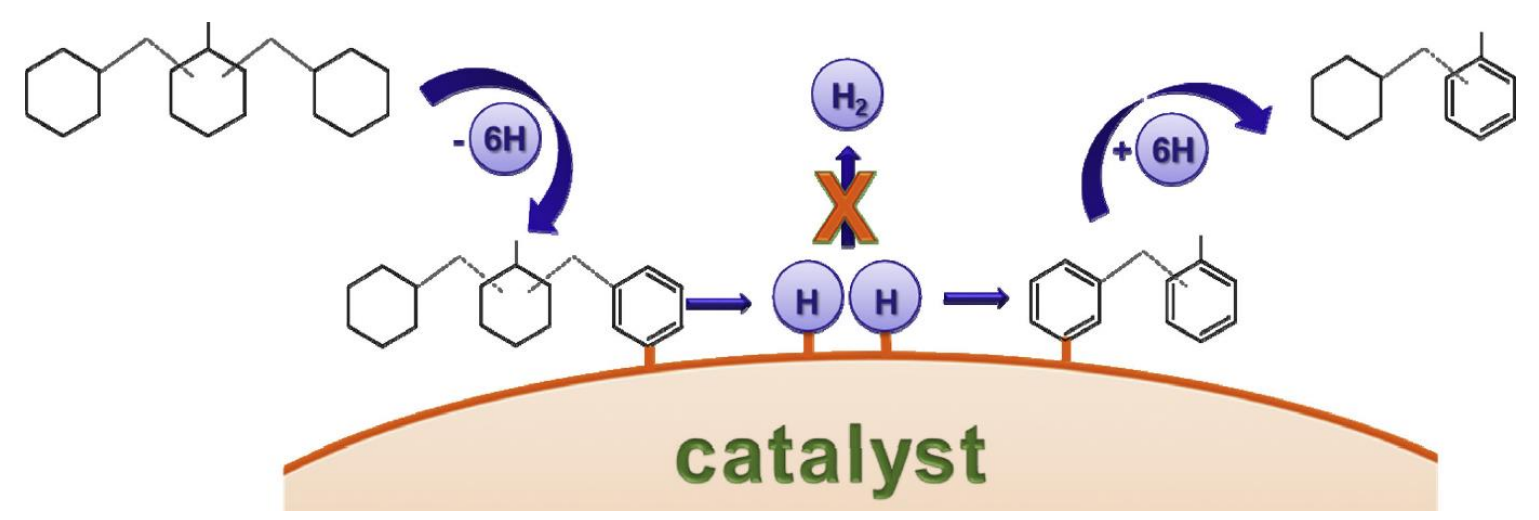

Figure 6. Reaction scheme of the proposed reaction mechanism for the transfer hydrogenation between $\mathrm{H} 2-$ benzyltoluene and $\mathrm{H} 2+$ dibenzyltoluene. Reprinted with permission from [82].

On the other hand, the reactive distillation process is one of the concerns to provide the pure hydrogen and enhancement of dehydrogenation efficiency. Very briefly, reactive distillation is defined as the dehydrogenation and separation of $\mathrm{H} 2+$ from $\mathrm{H} 2-$ LOHC molecules at the same time and in the same reaction volume. Very recently, Geißelbrecht et al. reported a reactive distillation setup for improving the dehydrogenation rate of H12-BT under very mild reaction conditions [84]. Importantly, the dehydrogenation efficiency of H12-BT with this setup achieved a $50 \%$ increase of overall hydrogen release rate compared to liquid-phase dehydrogenation with a $\mathrm{Pt} / \mathrm{Al}_{2} \mathrm{O}_{3}$ catalyst at $218{ }^{\circ} \mathrm{C}$ and $30 \mathrm{kPa}$. Authors also conducted several breakthrough experiments to better understand this LOHC system, which are not discussed in this review. Finally, such low temperature dehydrogenation reaction conditions using reactive distillation can enhance the use of this LOHC system for many hydrogen storage applications.

\subsection{Heterocyclic Compounds}

Compared with cyclic aromatic hydrocarbons, N-heterocyclic-based LOHCs have attracted significant attention due to their reversibility, favorable kinetics and thermodynamics, and low dehydrogenation temperature, etc., as suggested by the Pez and Crabtree research groups [24,31]. In addition, other heterocyclics like dibenzofuran (O-heteroatom) and dibenzothiophene (S-heteroatom), are chosen less frequently because they give undesired products during hydrogenolysis [85]. As mentioned earlier, the N-heterocyclic system (NEC) has been investigated extensively in several important reviews. For this reason, the present section focuses on indole derivatives which are similar structures to carbazole [86]. Moreover, we briefly describe other important N-based LOHC systems, such as phenazine and 2-n-methylbenzyl pyridine, and tabulated physicochemical properties of the aforementioned compounds (Table 1).

\subsubsection{Hydrogenation/Dehydrogenation of Indole Derivatives}

Among all N-heterocyclics, indole and its derivatives have suitable kinetic and thermodynamic properties, motivating exploration of these compounds for LOHC applications. Moreover, these are similar structures to carbazole derivatives, and their low melting points, lower dehydrogenation temperatures, and satisfactory storage capacities have made them attractive as potential LOHC systems [86]. As suggested by Jessop and coworkers, alkyl substitution on the pyrrolidine rings of indole derivatives significantly reduces enthalpy though it minimizes the storage capacity [87]. With this attention, few synthetically benign alkyl-substituted indoles have been widely explored in LOHC technology. Herein, we highlight catalytic hydrogenation and dehydrogenation of N-methyl indole/N-methyl perhydroindole, N-ethylindole/N-ethylperhydroindole, 2-methylindole/2-methyl perhydroindole, and 1,2-dimethyl indole/1,2-dimethyl perhydroindole LOHC systems (Figure 7). 


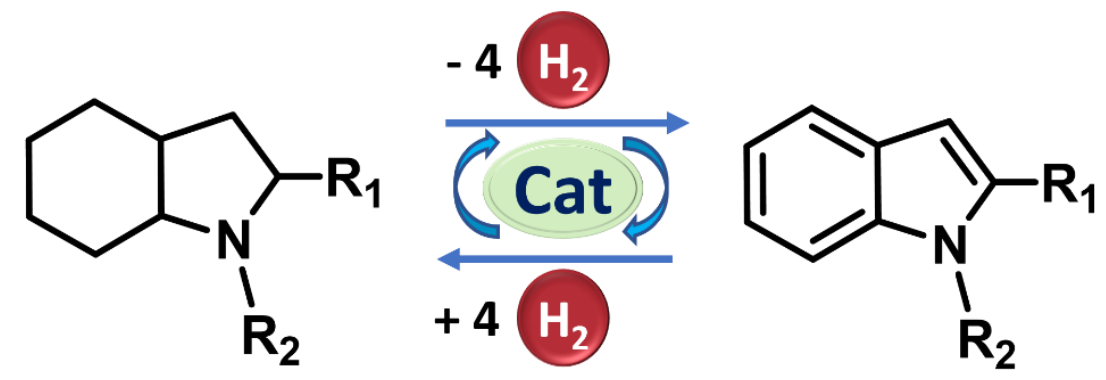

$$
\begin{aligned}
& \text { 1. } R_{1}=H, R_{2}=C_{3} ; 2 . R_{1}=C_{3}, R_{2}=H \\
& \text { 3. } R_{1}=C_{3}, R_{2}=C_{3} ; 4 \cdot R_{1}=C_{2} H_{5}, R_{2}=H
\end{aligned}
$$

Figure 7. Schematic illustration of the LOHC system using perhydro-indole derivatives/ indole derivatives.

In 2015, Dong et al. reported N-ethyl indole (NEID) as a LOHC candidate molecule and its physicochemical properties are well-suited for on-board automotive applications [88]. It possesses a melting point of $-17.8^{\circ} \mathrm{C}$, boiling point of $253.5^{\circ} \mathrm{C}$, and flashpoint of $107.1^{\circ} \mathrm{C}$, as well as attaining a $5.23 \mathrm{wt} \%$ hydrogen storage density. Hydrogenation of NEID was conducted at $9 \mathrm{MPa}$ over $160-190^{\circ} \mathrm{C}$ using $5 \mathrm{wt} \%$ of $\mathrm{Ru}-\mathrm{Al}_{2} \mathrm{O}_{3}$ catalyst. The reaction rate rises sharply with increasing temperatures. The apparent activation energy for consumption of NEID was $62.4 \mathrm{~kJ} / \mathrm{mol}$, which is comparatively lower than NEC $(99.5 \mathrm{~kJ} / \mathrm{mol})$, and identified hydrogenation products of NEID were as follows: $\mathrm{NEID} \rightarrow 2 \mathrm{H}-\mathrm{NEID} \rightarrow 4 \mathrm{H}-\mathrm{NEID} \rightarrow 8 \mathrm{H}-\mathrm{NEID}$. Afterwards, the maximum concentration of dehydrogenated product was achieved in $60 \mathrm{~min}$ using $5 \mathrm{wt} \% \mathrm{Pd} / \mathrm{Al}_{2} \mathrm{O}_{3}$ at $101 \mathrm{kPa}$ and $190^{\circ} \mathrm{C}$. Finally, dynamic sampling mass spectrum (DSMS) results revealed no side-product formation and produced hydrogen gas in high purity during dehydrogenation process.

In 2016, Li et al. developed another indole derivative, 2-methylindole (2-MID), with a storage capacity of $5.76 \mathrm{wt} \%$ [89]. The melting point of 2-MID $\left(57^{\circ} \mathrm{C}\right)$ is lower than NEC $\left(70{ }^{\circ} \mathrm{C}\right)$, and the activation barrier $(21 \mathrm{~kJ} / \mathrm{mol})$ for hydrogenation is kinetically facile compared to NEC and NEID. Hydrogenation of 2-MID was studied with the $\mathrm{Ru} / \mathrm{Al}_{2} \mathrm{O}_{3}(5 \mathrm{wt} \%)$ catalyst, a hydrogen pressure of $7 \mathrm{MPa}$, and a temperature range of $120-170{ }^{\circ} \mathrm{C}$. The temperature dependent hydrogenation reaction and theoretical studies revealed the reaction route (2-MID to $8 \mathrm{H}-2-\mathrm{MID})$ through kinetically stable intermediates (Figure 8). On the other hand, the fully dehydrogenated product of 8H-2-MID was achieved with $5 \mathrm{wt} \%$ of $\mathrm{Pd} / \mathrm{Al}_{2} \mathrm{O}_{3}$ catalyst in $4 \mathrm{~h}$ at $190^{\circ} \mathrm{C}$, and the apparent activation energy during this process was estimated to be $27.1 \mathrm{~kJ} / \mathrm{mol}$.

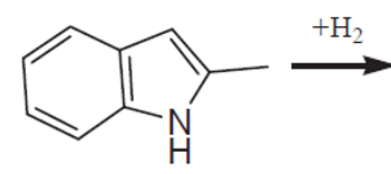

2-MID

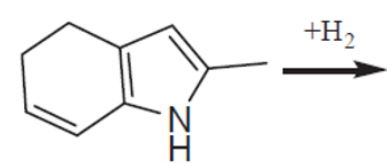

2H-2-MID

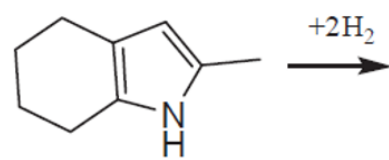

4H-2-MID<smiles>CC1CC2CCCCC2N1</smiles>

8H-2-MID

Figure 8. The schematic hydrogenation route from 2-MID to 8H-2-MID. Reprinted with permission from [89].

In 2018, Yang et al. developed an alkylated indole derivative, 1-methyl indole (NMID). Its low melting point of $-20{ }^{\circ} \mathrm{C}$ and relatively low vapor pressure exhibits this material well-suited for LOHC technology [90]. Similar to 2-MID, Ru and Pd on alumina support catalysts were selected for hydrogenation and dehydrogenation reactions. Furthermore, DSMS experiments proved that 99.99\% purity $\mathrm{H}_{2}$ gas without any side-product formation was detected during dehydrogenation (Figure 9). Very recently, Dong et al. proposed another indole derivative, 1,2-dimethylindole (1,2-DMID) which possess storage capacity of $5.23 \mathrm{wt} \%$ [91]. The chemical stability of 1,2-DMID during 
hydrogenation/dehydrogenation and moderately favorable physicochemical properties (melting point of $55^{\circ} \mathrm{C}$, boiling point of $260^{\circ} \mathrm{C}$ ) facilitate use of this hydrogen storage material for on-board applications. Similar catalysts (typically for the 2-MID LOHC system) were used during this catalysis reaction, as well.

(a)

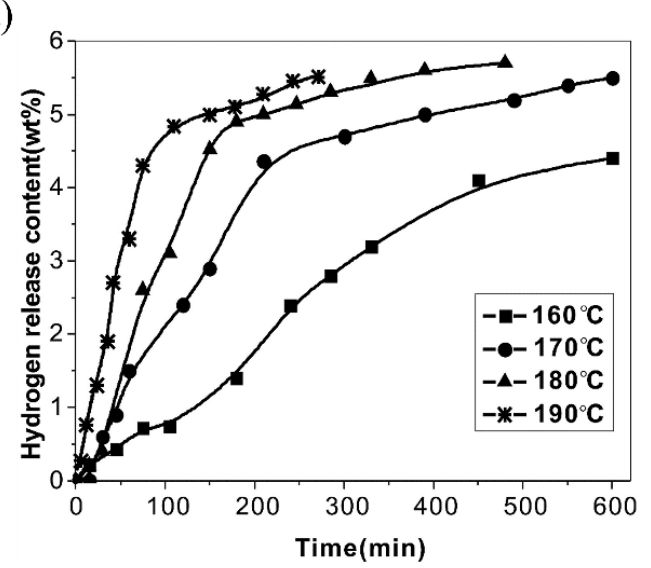

(b)

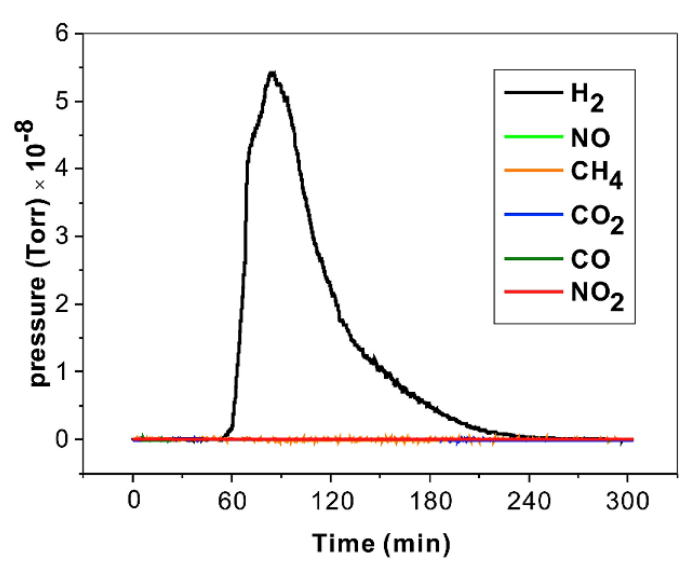

Figure 9. (a) The time-dependent hydrogen release curves of 8H-NMID dehydrogenation at different temperatures. (b) DSMS spectra of hydrogen gas released from the dehydrogenation process at $180^{\circ} \mathrm{C}$. Reprinted with permission from [90].

\subsubsection{Hydrogenation/Dehydrogenation of Phenazine}

Another promising N-heterocyclic LOHC system, perhydro-phenazine/phenazine (Figure 10) exhibits a hydrogen storage capacity of $7.2 \mathrm{wt} \%$, as reported by Kempe et al. [92]. Interestingly, octahydro-phenazine was synthesized sustainably from hydrogenolysis of lignin product and ammonia (Figure 11a). Owning to the thermally and chemically inert nature of the amorphous silicon carbonitride $(\mathrm{SiCN})$ matrix, it was selected for synthesis of the bimetallic nanocomposite $\mathrm{Pd}_{2} \mathrm{Ru} @ S i C N_{\text {catalyst. }}$ Utilizing this catalyst, quantitative dehydrogenation of octahydro-phenazine (obtained from lignin) to phenazine was performed, followed by used in hydrogen storage cycles. In the view of hydrogenation reaction, the dioxane/water-dissolved phenazine at $150{ }^{\circ} \mathrm{C}$ and $5 \times 10^{3} \mathrm{kPa}$ of $\mathrm{H}_{2}$ pressure, yielded a high hydrogenation rate due to the influence of the aqueous solvent medium. On the other hand, this candidate molecule performed well in terms of reversibility and stability, as confirmed by better conversion of tetradecahydrophenazine to phenazine at $190^{\circ} \mathrm{C}$ using diglyme as the solvent. Moreover, the LOHC candidate molecule showed hydrogen uptake/release with small variations over seven consecutive cycles. Further, no carbon monoxide (CO) was detected, and high purity hydrogen gas was released (Figure 11b).
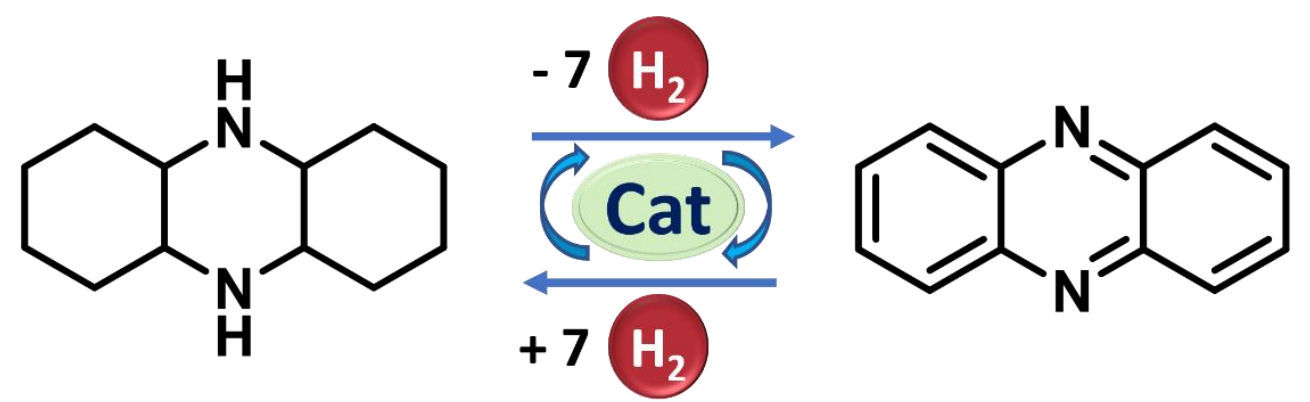

Figure 10. The schematic illustration of perhydro-phenazine/phenazine LOHC system. 
(a)

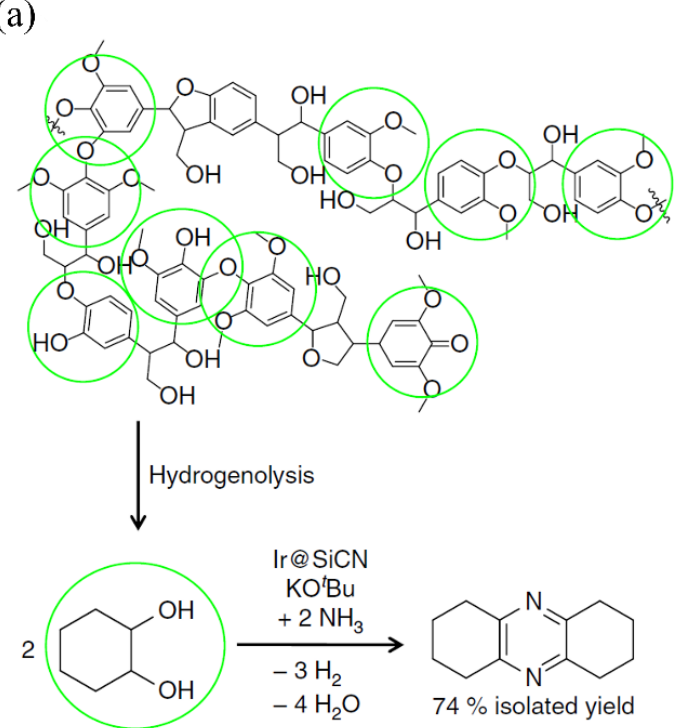

(b)

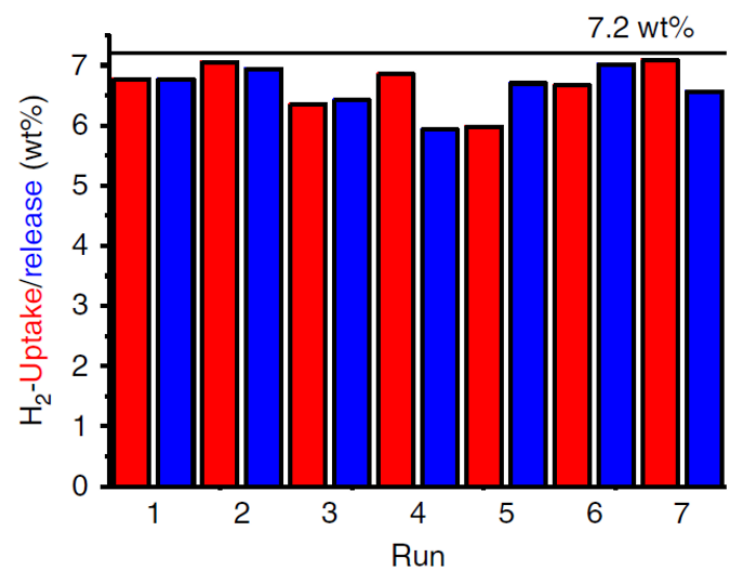

Figure 11. (a) A section of the lignin structure with alkoxybenzene subunits marked by green circles (top). Lignin can be converted to cyclohexane-1,2-diol using existing methodologies (hydrogenolysis). Synthesis of octahydro-phenazine from cyclohexane-1,2-diol and ammonia (bottom). (b) Hydrogen uptake and release over consecutive cycles were calculated by GC and GC-MS analysis, based on the preceding step. Reprinted with permission from [92].

\subsubsection{Hydrogenation/Dehydrogenation of 2-(n-Methylbenzyl Pyridine)}

Recently, a new potential LOHC candidate molecule, 2-(n-methylbenzyl pyridine) (MBP), was adjoined in N-heterocyclic compounds (Figure 12). Suh and coworkers proposed the MBP hydrogen carrier molecule which stores $6.15 \mathrm{wt} \%$ hydrogen density and exists in the liquid state at ambient conditions [93]. Theoretical calculations and the ease of MBP synthesis satisfy thermodynamic challenges and technical availability (Figure 13a). Upon examining various synthesized and commercial catalysts, $\mathrm{Ru} / \mathrm{Al}_{2} \mathrm{O}_{3}$ performed well for hydrogenation, whereas $\mathrm{Pd} / \mathrm{C}$ showed better activity for dehydrogenation. MBP is less viscous $\left(5.9 \mathrm{cP}\right.$ at $\left.25^{\circ} \mathrm{C}\right)$ compared to dibenzyl toluene (DBT, $\left.37.8 \mathrm{cP}\right)$ and ethylene glycol $(16.1 \mathrm{cP})$, and the copper strip corrosion test revealed that MBP is favorable for transportation. Furthermore, MBP is stable and maintains consistent hydrogen storage efficiency over three consecutive cycles (Figure 13b).
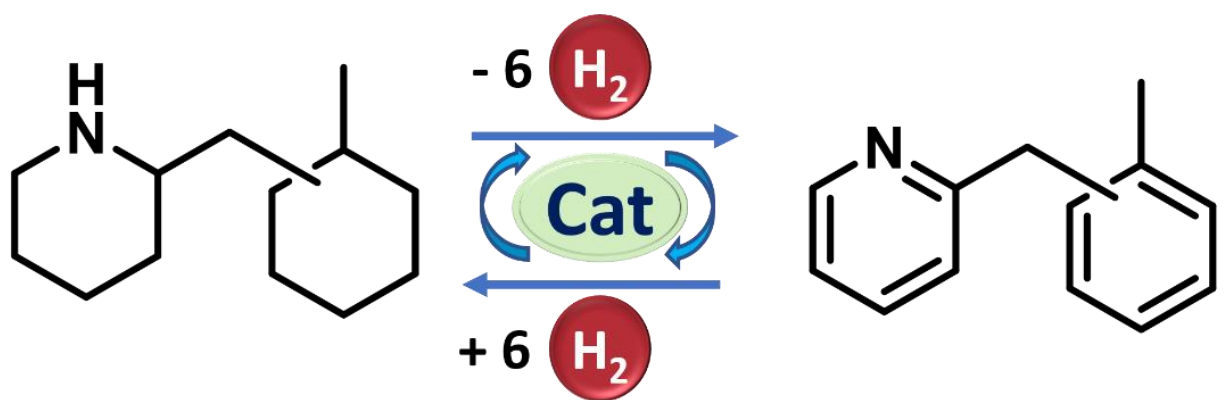

Figure 12. The schematic illustration of the perhydro-2-(n-methylbenzyl pyridine)/2-(n-methylbenzyl pyridine) LOHC system. 
(a)

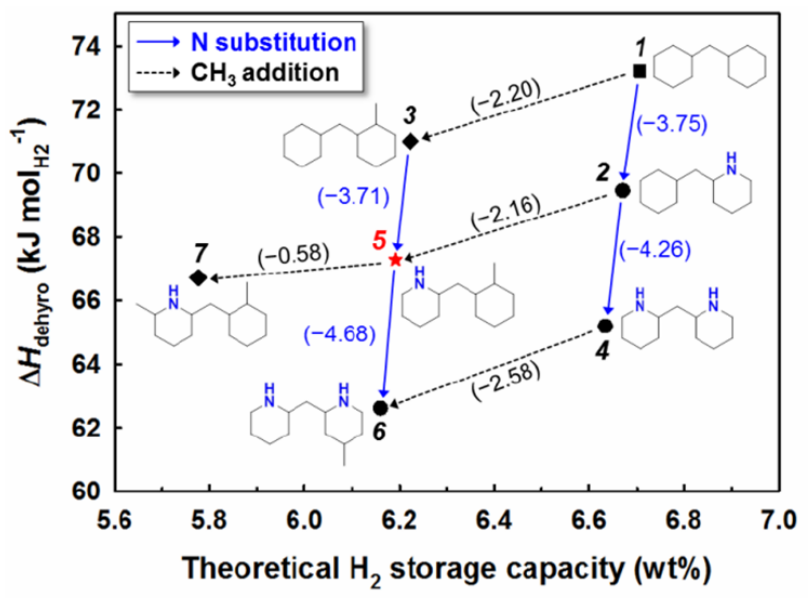

(b)

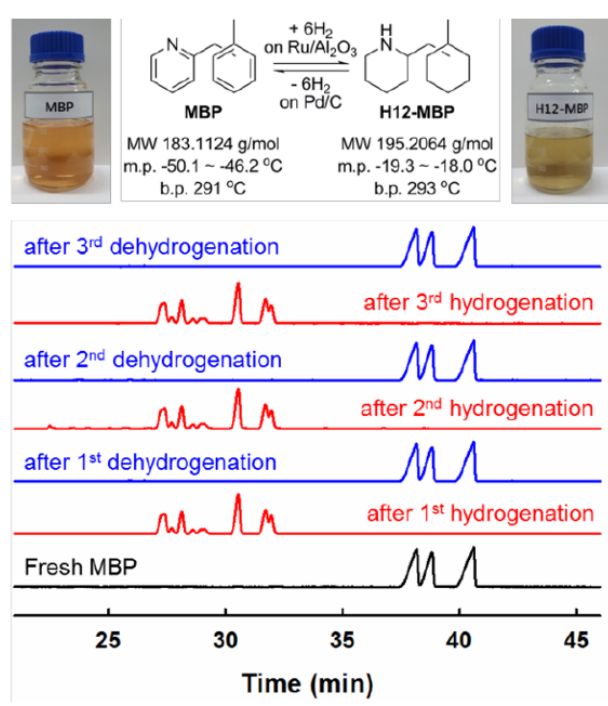

Figure 13. (a) Effect of $\mathrm{N}$-substitution and $-\mathrm{CH}_{3}$ addition to dicyclohexylmethane on the calculated dehydrogenation enthalpy value and theoretical hydrogen storage capacity. The values in parentheses indicate the difference of $\Delta \mathrm{H}_{\text {dehydro }}$ between the molecules in each arrow. (b) GC chromatograms of product mixtures obtained thorough three cycles of MBP hydrogenation over $1 \mathrm{wt} \% \mathrm{Ru} / \mathrm{Al}_{2} \mathrm{O}_{3}$ and H12-MBP dehydrogenation over $1 \mathrm{wt} \% \mathrm{Pd} / \mathrm{C}$. Reprinted with permission from [93].

The development of an efficient catalytic system for dehydrogenation is highly dependent on the support materials' activities and stabilities, it will minimize the dehydrogenation temperature. The same research group was motivated by these concerns and developed a Pd-based heterogeneous catalyst (Pd/CCA) using a carbon-coated alumina (CCA) support [94]. Compared with pure carbon and alumina, the most stable CCA support exhibited excellent performance in terms of activity and stability at a carbon-content of $3.3 \mathrm{wt} \%(\mathrm{Pd} / 3.3 \mathrm{CCA})$. In addition, the authors examined catalyst behavior, stability, Pd loading, and particle size through various techniques such as TEM, TPD, and TG-MS, etc. In this report, $\mathrm{Pd} / 3.3 \mathrm{CCA}$ displayed better conversion and selectivity of H12-MBP and achieved a high hydrogen yield compared to $\mathrm{Pd} / \mathrm{Al}_{2} \mathrm{O}_{3}$ and $\mathrm{Pd} / \mathrm{C}$ at $250{ }^{\circ} \mathrm{C}$ for $4 \mathrm{~h}$ (Table 2). Furthermore, a carbon-coated silica-alumina support (CCSA) showed improved catalytic activity over $\mathrm{SiO}_{2}-\mathrm{Al}_{2} \mathrm{O}_{3}$ under similar reaction conditions $\left(\mathrm{Pd} / 3.3 \mathrm{CCSA}>\mathrm{Pd} / \mathrm{SiO}_{2}-\mathrm{Al}_{2} \mathrm{O}_{3}\right)$. Finally, these catalysts may pave the way toward novel alumina surface modifications to achieve better catalyst stability and activity during dehydrogenation processes.

Table 2. Activity results in the dehydrogenation of $\mathrm{H} 12-\mathrm{MBP}$ at $250{ }^{\circ} \mathrm{C}$ for $4 \mathrm{~h}$ [a].

\begin{tabular}{cccc}
\hline Catalyst & H12-MBP Conversion [mol\%] & Selectivity to H0-MBP [mol\%] & $\mathbf{H}_{\mathbf{2}}$ Yield [mol\%] \\
\hline $\mathrm{Pd} / \mathrm{Al}_{2} \mathrm{O}_{3}$ & 65.3 & 63.3 & 53.3 \\
$\mathrm{Pd} / 2.0 \mathrm{CCA}$ & 72.1 & 75.4 & 63.2 \\
$\mathrm{Pd} / 3.3 \mathrm{CCA}$ & 80.6 & 76.4 & 71.1 \\
$\mathrm{Pd} / 4.5 \mathrm{CCA}$ & 65.5 & 62.3 & 53.1 \\
$\mathrm{Pd} / 6.0 \mathrm{CCA}$ & 60.1 & 29.2 & 38.8 \\
$\mathrm{Pd} / \mathrm{C}$ & 59.0 & 78.2 & 52.6 \\
\hline
\end{tabular}

[a] Calculated by GC results.

\section{Theoretical Effort for Development of LOHCs}

The growing interest in LOHC technology has encouraged theoretical evaluation for an in-depth understanding of catalysis and related catalytic aspects. Notably, DFT calculations have gained attention for proposing associated catalyst models and benefit the investigation of mechanistic reaction pathways on numerous catalyst species and surfaces [22,95]. Though there are several experimental 
reports on LOHCs, insights into reaction pathways, the role of the catalyst and its corresponding surface effects, and the contributions of reactants/products during catalysis are still in infancy. Recently, a few reports on catalytic dehydrogenation of octahydroindole and 2-methyloctahydroindole on $\mathrm{Pt}(111)$ surfaces [86,96] and decalin dehydrogenation over Pd- and Pt-supported catalysts [97] have been investigated. Herein, we briefly describe one recent catalytic dehydrogenation study on a metal surface using DFT calculations.

Among all, catalytic dehydrogenation of $\mathrm{MCH}$ has attracted dramatically due to the rapid increase of its practical utilization. Due to Pt-based catalysts' high activity in $\mathrm{MCH}$ dehydrogenation, understanding the $\mathrm{MCH}$ dehydrogenation mechanism theoretically on $\mathrm{Pt}$ surfaces is vitally important. Very recently, Chen et al. reported the step-by-step dehydrogenation of $\mathrm{MCH}$ to toluene on a $\mathrm{Pt}(111)$ surface using DFT calculations [98]. To understand the adsorption pathway, the authors optimized the most stable adsorption and co-adsorption configurations for reactants, intermediates, and products on four adsorption $\mathrm{Pt}(111)$ surface sites (denoted as top position, bridge position, hcp hollow, and fcc hollow; Figure 14a). Moreover, C-C bond length studies revealed shrinkage of each product bond length during $\mathrm{MCH}$ dehydrogenation. The six-step $\mathrm{MCH}$ dehydrogenation energy profile on the $\mathrm{Pt}(111)$ surface indicated that the first step is rate limiting step and the second and fourth step intermediates can be formed in thermodynamically stable molecules 4-methylcyclohexene and methylcyclohexadiene, respectively, which is consistent to experimental results (Figure 14b). Therefore, clarification of the stepwise dehydrogenation process further progress in the design of novel Pt-based catalysts.

(a)

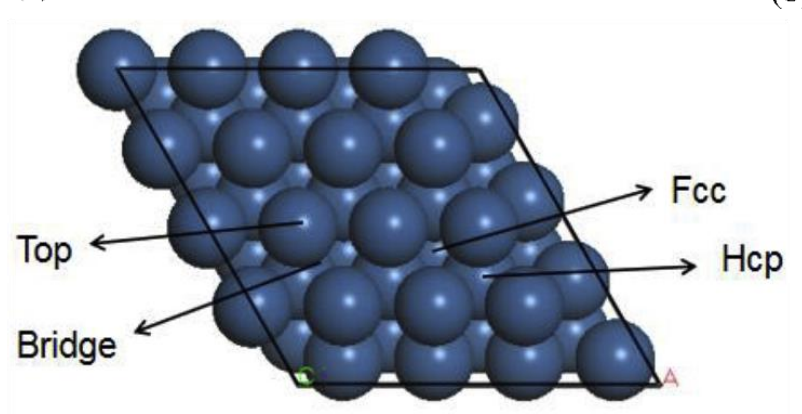

Figure 14. (a) Optimized surface structure of $\mathrm{Pt}(111)$. dehydrogenation on $\mathrm{Pt}(111)$. Reprinted with permission from [98]. (b)

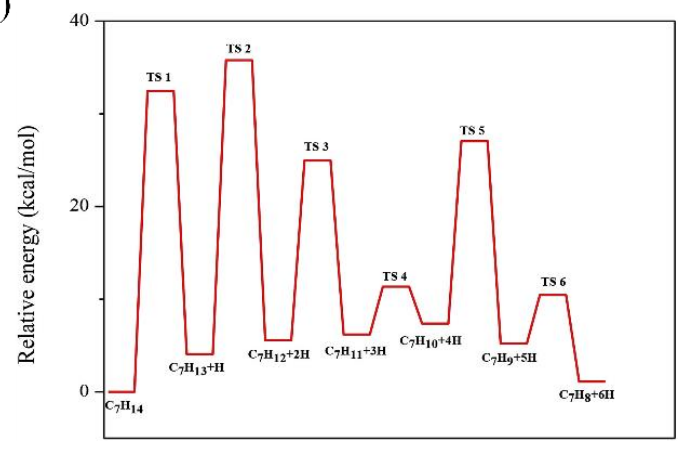

(b) Complete energy profile for $\mathrm{MCH}$

\section{Conclusions and Perspective}

The depletion of fossil-fuels and limited access to use renewable, sustainable energy leads to a quest for alternative energy sources to fulfill the modern world's energy demands. Hydrogen storage technology is endowed as a clean and efficient system, which prevent the global warming and keep the planet safe. Since hydrogen storage and transportation are cost-effective and unsafe, the current technologies are highly dependent on this new class of alternative systems: LOHCs. In this context, extensive research progress is devoted to finding efficient candidate molecules for practical application. This review covered various essential aspects to development of high performance LOHCs for targeted applications. Additionally, the reviewed molecules and systems have their own merits and drawbacks from numerous viewpoints, such as storage capacity, stability, catalytic medium, physicochemical properties, toxicology, biodegradability, etc. However, the highlighted compounds are role models for future investigation of LOHC candidates.

In general, LOHCs have attractive features that are very similar to crude oil; thereby, these systems are suitable for use with existing energy infrastructure. In this regard, toluene and dibenzyl toluene LOHC systems show the highest potential for large-scale production. However, there is a need for further development in LOHC technology. Especially in the thermodynamic view, as lower dehydrogenation enthalpies facilitate less heat demand and it benefits the molecular stability, 
and recyclability of the candidate molecules over multiple cycles. Another figure catalytic medium pointed out that catalyst's efficiency with a superb material support may reduce the activation energy barrier for fruitful dehydrogenation at lower temperatures. Besides, performing theoretical evaluation is necessary for developing suitable model catalysts and understanding the mechanistic aspects of (de)hydrogenation. The latter, technical availability, toxicity profile, and biodegradability were examined for very few LOHC systems. Hence, hazard assessment and economic evaluation needs to be addressed to make this technology practical. Overall, the scientific community and industry's joint effort can meet these challenges, benefiting future implementation of this attractive technology across broad applications.

Author Contributions: P.C.R.: Conceptualization, formal analysis, visualization, writing—original draft; M.Y.: Conceptualization, funding acquisition, supervision, validation, writing - review and editing. All authors have read and agreed to the published version of the manuscript.

Funding: This work was supported by National Research Foundation of Korea (NRF) grant funded by Ministry of Science and ICT (NRF-2019H1D3A1A01102895).

Conflicts of Interest: The authors declare no conflict of interest.

\section{References}

1. REN21. Renewables 2017. In Global Status Report; REN21: Montreal, QC, Canada, 2017.

2. Kim, S.J.; Cho, J.-H.; Lee, K.-Y.; Cho, B.W.; Chung, K.Y.; Kim, J.-Y. MnO ${ }_{x}$-Carbon Black-embedded $\mathrm{LiFePO}_{4}$ $\left(\mathrm{MnO}_{x} / \mathrm{C}-\mathrm{LFP}\right)$ as a Cathode Material for High-Power Li-Ion Batteries. Bull. Korean Chem. Soc. 2019, 40, 317-323. [CrossRef]

3. Eberle, D.U.; von Helmolt, D.R. Sustainable transportation based on electric vehicle concepts: A brief overview. Energy Environ. Sci. 2010, 3, 689-699. [CrossRef]

4. Barreto, L.; Makihira, A.; Riahi, K. The hydrogen economy in the 21st century: A sustainable development scenario. Int. J. Hydrogen Energy 2003, 28, 267-284. [CrossRef]

5. Sartbaeva, A.; Kuznetsov, V.L.; Wells, S.A.; Edwards, P.P. Hydrogen nexus in a sustainable energy future. Energy Environ. Sci. 2008, 1, 79-85. [CrossRef]

6. Saxena, R.C.; Seal, D.; Kumar, S.; Goyal, H.B. Thermo-chemical routes for hydrogen rich gas from biomass: A review. Renew. Sustain. Energy Rev. 2008, 12, 1909-1927. [CrossRef]

7. Jones, L.W. Liquid Hydrogen as a Fuel for the Future. Science 1971, 174, 367. [CrossRef] [PubMed]

8. Winsche, W.E.; Hoffman, K.C.; Salzano, F.J. Hydrogen: Its Future Role in the Nation's Energy Economy. Science 1973, 180, 1325-1332. [CrossRef] [PubMed]

9. Momirlan, M.; Veziroglu, T.N. The properties of hydrogen as fuel tomorrow in sustainable energy system for a cleaner planet. Int. J. Hydrogen Energy 2005, 30, 795-802. [CrossRef]

10. Bockris, J.O.M. The hydrogen economy: Its history. Int. J. Hydrogen Energy 2013, 38, 2579-2588. [CrossRef]

11. Abbas, S.A.; Ma, A.; Seo, D.; Lim, Y.J.; Jung, G.D.; Nam, K.M. Application of Spiky Nickel Nanoparticles to Hydrogen Evolution Reaction. Bull. Korean Chem. Soc. 2020, 41, 1080-1085. [CrossRef]

12. Armaroli, N.; Balzani, V. The Hydrogen Issue. ChemSusChem 2011, 4, 21-36. [CrossRef] [PubMed]

13. Kim, J.H.; Kim, C.; Jeon, Y.; Kim, S. Hydrogen Production from Makgeolli Wastewater Using a Single-Chamber Microbial Electrolysis Cell. Bull. Korean Chem. Soc. 2020, 41, 150-155. [CrossRef]

14. Dalebrook, A.F.; Gan, W.; Grasemann, M.; Moret, S.; Laurenczy, G. Hydrogen storage: Beyond conventional methods. Chem. Commun. 2013, 49, 8735-8751. [CrossRef] [PubMed]

15. Felderhoff, M.; Weidenthaler, C.; von Helmolt, R.; Eberle, U. Hydrogen storage: The remaining scientific and technological challenges. Phys. Chem. Chem. Phys. 2007, 9, 2643-2653. [CrossRef]

16. Grochala, W.; Edwards, P.P. Thermal Decomposition of the Non-Interstitial Hydrides for the Storage and Production of Hydrogen. Chem. Rev. 2004, 104, 1283-1316. [CrossRef]

17. Sakintuna, B.; Lamari-Darkrim, F.; Hirscher, M. Metal hydride materials for solid hydrogen storage: A review. Int. J. Hydrogen Energy 2007, 32, 1121-1140. [CrossRef]

18. Chahine, R.; Bose, T.K. Low-pressure adsorption storage of hydrogen. Int. J. Hydrogen Energy 1994, 19, 161-164. [CrossRef] 
19. Amankwah, K.A.G.; Noh, J.S.; Schwarz, J.A. Hydrogen storage on superactivated carbon at refrigeration temperatures. Int. J. Hydrogen Energy 1989, 14, 437-447. [CrossRef]

20. Rosi, N.L.; Eckert, J.; Eddaoudi, M.; Vodak, D.T.; Kim, J.; O’Keeffe, M.; Yaghi, O.M. Hydrogen Storage in Microporous Metal-Organic Frameworks. Science 2003, 300, 1127-1129. [CrossRef]

21. DOE Technical Targets for Onboard Hydrogen Storage for Light-Duty Vehicles. Available online: https: //energy.gov/eere/fuelcells/doe-technicaltargets-onboard-hydrogen-storage-light-duty-vehicles (accessed on 30 March 2017).

22. Modisha, P.M.; Ouma, C.N.M.; Garidzirai, R.; Wasserscheid, P.; Bessarabov, D. The Prospect of Hydrogen Storage Using Liquid Organic Hydrogen Carriers. Energy Fuels 2019, 33, 2778-2796. [CrossRef]

23. Aakko-Saksa, P.T.; Cook, C.; Kiviaho, J.; Repo, T. Liquid organic hydrogen carriers for transportation and storing of renewable energy—Review and discussion. J. Power Sources 2018, 396, 803-823. [CrossRef]

24. Crabtree, R.H. Nitrogen-Containing Liquid Organic Hydrogen Carriers: Progress and Prospects. ACS Sustain. Chem. Eng. 2017, 5, 4491-4498. [CrossRef]

25. Wild, V.J.; Friedrich, T.; Cooper, A.; Toseland, B.; Muraro, G.; Tegrotenhuis, W.; Wang, Y.; Humble, P.; Karim, A. Liquid Organic Hydrogen Carriers (LOHC): An auspicious alternative to conventional hydrogen storage technologies. In Proceedings of the 18th World Hydrogen Energy Conference, Essen, Germany, 16-20 May 2010; Volume 78, pp. 189-197.

26. Cooper, A.C.; Campbell, K.M.; Pez, G.P. An integrated hydrogen storage and delivery approach using organic liquid-phase carriers. In Proceedings of the 16th World Hydrogen Energy Conference, Lyon, France, 13-16 June 2006; pp. 1-12.

27. Taube, M.; Rippin, D.W.T.; Cresswell, D.L.; Knecht, W. A system of hydrogen-powered vehicles with liquid organic hydrides. Int. J. Hydrogen Energy 1983, 8, 213-225. [CrossRef]

28. Klvana, D.; Chaouki, J.; Kusohorsky, D.; Chavarie, C.; Pajonk, G.M. Catalytic storage of hydrogen: Hydrogenation of toluene over a nickel/silica aerogel catalyst in integral flow conditions. Appl. Catal. 1988, 42, 121-130. [CrossRef]

29. Itoh, N.; Xu, W.C.; Hara, S.; Sakaki, K. Electrochemical coupling of benzene hydrogenation and water electrolysis. Catal. Today 2000, 56, 307-314. [CrossRef]

30. Kariya, N.; Fukuoka, A.; Ichikawa, M. Efficient evolution of hydrogen from liquid cycloalkanes over Pt-containing catalysts supported on active carbons under "wet-dry multiphase conditions". Appl. Catal. A 2002, 233, 91-102. [CrossRef]

31. Pez, G.P.; Scott, A.R.; Cooper, A.C.; Cheng, H. Hydrogen Storage Reversible Hydrogenated of Pi-Conjugated Substrates. U.S. Patent 7,101,530 B2, 4 November 2005.

32. Sotoodeh, F.; Smith, K.J. Kinetics of Hydrogen Uptake and Release from Heteroaromatic Compounds for Hydrogen Storage. Ind. Eng. Chem. Res. 2010, 49, 1018-1026. [CrossRef]

33. Sobota, M.; Nikiforidis, I.; Amende, M.; Zanón, B.S.; Staudt, T.; Höfert, O.; Lykhach, Y.; Papp, C.; Hieringer, W.; Laurin, M.; et al. Dehydrogenation of Dodecahydro-N-ethylcarbazole on Pd/Al2O3 Model Catalysts. Chem. Eur. J. 2011, 17, 11542-11552. [CrossRef]

34. Sotoodeh, F.; Huber, B.J.M.; Smith, K.J. Dehydrogenation kinetics and catalysis of organic heteroaromatics for hydrogen storage. Int. J. Hydrogen Energy 2012, 37, 2715-2722. [CrossRef]

35. Campbell, P.G.; Zakharov, L.N.; Grant, D.J.; Dixon, D.A.; Liu, S.-Y. Hydrogen Storage by Boron-Nitrogen Heterocycles: A Simple Route for Spent Fuel Regeneration. J. Am. Chem. Soc. 2010, 132, 3289-3291. [CrossRef]

36. Luo, W.; Zakharov, L.N.; Liu, S.-Y. 1,2-BN Cyclohexane: Synthesis, Structure, Dynamics, and Reactivity. J. Am. Chem. Soc. 2011, 133, 13006-13009. [CrossRef] [PubMed]

37. Liu, S.-Y. Hydrogen Storage by Novel CBN Heterocycle Materials. Final Rep. 2015. [CrossRef]

38. Crabtree, R.H. Hydrogen storage in liquid organic heterocycles. Energy Environ. Sci. 2008, 1, 134-138. [CrossRef]

39. Müller, K.; Völkl, J.; Arlt, W. Thermodynamic Evaluation of Potential Organic Hydrogen Carriers. Energy Technol. 2013, 1, 20-24. [CrossRef]

40. Okada, Y.; Mikuriya, T.; Yasui, T.M. Large scale hydrogen energy storage transportation technology. "SPERA" system. Kem. Enjiniyaringu 2015, 60, 187-193.

41. Teichmann, D.; Stark, K.; Müller, K.; Zöttl, G.; Wasserscheid, P.; Arlt, W. Energy storage in residential and commercial buildings via Liquid Organic Hydrogen Carriers (LOHC). Energy Environ. Sci. 2012, 5, 9044-9054. [CrossRef] 
42. Haupt, A.; Müller, K. Integration of a LOHC storage into a heat-controlled CHP system. Energy 2017, 118, 1123-1130. [CrossRef]

43. Eypasch, M.; Schimpe, M.; Kanwar, A.; Hartmann, T.; Herzog, S.; Frank, T.; Hamacher, T. Model-based techno-economic evaluation of an electricity storage system based on Liquid Organic Hydrogen Carriers. Appl. Energy 2017, 185, 320-330. [CrossRef]

44. Niermann, M.; Drünert, S.; Kaltschmitt, M.; Bonhoff, K. Liquid organic hydrogen carriers (LOHCs)— Techno-economic analysis of LOHCs in a defined process chain. Energy Environ. Sci. 2019, 12, 290-307. [CrossRef]

45. Preuster, P.; Papp, C.; Wasserscheid, P. Liquid Organic Hydrogen Carriers (LOHCs): Toward a Hydrogen-free Hydrogen Economy. Acc. Chem. Res. 2017, 50, 74-85. [CrossRef]

46. Gianotti, E.; Taillades-Jacquin, M.; Rozière, J.; Jones, D.J. High-Purity Hydrogen Generation via Dehydrogenation of Organic Carriers: A Review on the Catalytic Process. ACS Catal. 2018, 8, 4660-4680. [CrossRef]

47. Biniwale, R.B.; Rayalu, S.; Devotta, S.; Ichikawa, M. Chemical hydrides: A solution to high capacity hydrogen storage and supply. Int. J. Hydrogen Energy 2008, 33, 360-365. [CrossRef]

48. Zhu, Q.-L.; Xu, Q. Liquid organic and inorganic chemical hydrides for high-capacity hydrogen storage. Energy Environ. Sci. 2015, 8, 478-512. [CrossRef]

49. Clot, E.; Eisenstein, O.; Crabtree, R.H. Computational structure-activity relationships in $\mathrm{H} 2$ storage: How placement of $\mathrm{N}$ atoms affects release temperatures in organic liquid storage materials. Chem. Commun. 2007, 2231-2233. [CrossRef] [PubMed]

50. Wang, Z.; Belli, J.; Jensen, C.M. Homogeneous dehydrogenation of liquid organic hydrogen carriers catalyzed by an iridium PCP complex. Faraday Discuss. 2011, 151, 297-305. [CrossRef] [PubMed]

51. Yamaguchi, R.; Ikeda, C.; Takahashi, Y.; Fujita, K.-I. Homogeneous Catalytic System for Reversible Dehydrogenation-Hydrogenation Reactions of Nitrogen Heterocycles with Reversible Interconversion of Catalytic Species. J. Am. Chem. Soc. 2009, 131, 8410-8412. [CrossRef]

52. Shimbayashi, T.; Fujita, K.-I. Metal-catalyzed hydrogenation and dehydrogenation reactions for efficient hydrogen storage. Tetrahedron 2020, 76, 130946. [CrossRef]

53. Boufaden, N.; Akkari, R.; Pawelec, B.; Fierro, J.L.G.;Zina, M.S.; Ghorbel, A. Dehydrogenation of methylcyclohexane to toluene over partially reduced silica-supported Pt-Mo catalysts. J. Mol. Catal. A Chem. 2016, 420, 96-106. [CrossRef]

54. Pande, J.V.; Shukla, A.; Biniwale, R.B. Catalytic dehydrogenation of cyclohexane over Ag-M/ACC catalysts for hydrogen supply. Int. J. Hydrogen Energy 2012, 37, 6756-6763. [CrossRef]

55. Modisha, P.; Gqogqa, P.; Garidzirai, R.; Ouma, C.N.M.; Bessarabov, D. Evaluation of catalyst activity for release of hydrogen from liquid organic hydrogen carriers. Int. J. Hydrogen Energy 2019, 44, 21926-21935. [CrossRef]

56. Papp, C.; Wasserscheid, P.; Libuda, J.; Steinrück, H.-P. Liquid Organic Hydrogen Carriers: Surface Science Studies of Carbazole Derivatives. Chem. Rec. 2014, 14, 879-896. [CrossRef] [PubMed]

57. Cooper, A.C. Hydrogen storage and delivery by reversible hydrogenation of liquid-phase hydrogen carriers. Pap. Am. Chem. Soc. 2005, 50, 271.

58. Daubert, T.E.; Danner, R.P. Physical and Thermodynamic Properties of Pure Chemicals; Taylor and Francis: London, UK, 1997.

59. Amende, M.; Gleichweit, C.; Schernich, S.; Höfert, O.; Lorenz, M.P.A.; Zhao, W.; Koch, M.; Obesser, K.; Papp, C.; Wasserscheid, P.; et al. Size and Structure Effects Controlling the Stability of the Liquid Organic Hydrogen Carrier Dodecahydro-N-ethylcarbazole during Dehydrogenation over Pt Model Catalysts. J. Phys. Chem. Lett. 2014, 5, 1498-1504. [CrossRef] [PubMed]

60. Fraunhofer IZM. Environmental Evaluation Methods. Toxic Potential Indicator (TPI). 2018. Available online: https://www.izm.fraunhofer.de/en/abteilungen/environmental_reliabilityengineering/key_research_ areas/environmental_assessmentandecodesign/toxic-potential-indicator-tpi-.html (accessed on 19 June 2018).

61. Brückner, N.; Obesser, K.; Bösmann, A.; Teichmann, D.; Arlt, W.; Dungs, J.; Wasserscheid, P. Evaluation of Industrially Applied Heat-Transfer Fluids as Liquid Organic Hydrogen Carrier Systems. ChemSusChem 2014, 7, 229-235. [CrossRef] [PubMed]

62. Markiewicz, M.; Zhang, Y.-Q.; Empl, M.T.; Lykaki, M.; Thöming, J.; Steinberg, P.; Stolte, S. Hazard assessment of quinaldine-, alkylcarbazole-, benzene- and toluene-based liquid organic hydrogen carrier (LOHCs) systems. Energy Environ. Sci. 2019, 12, 366-383. [CrossRef] 
63. Müller, K.; Stark, K.; Emel'yanenko, V.N.; Varfolomeev, M.A.; Zaitsau, D.H.; Shoifet, E.; Schick, C.; Verevkin, S.P.; Arlt, W. Liquid Organic Hydrogen Carriers: Thermophysical and Thermochemical Studies of Benzyl- and Dibenzyl-toluene Derivatives. Ind. Eng. Chem. Res. 2015, 54, 7967-7976. [CrossRef]

64. He, T.; Pei, Q.; Chen, P. Liquid organic hydrogen carriers. J. Energy Chem. 2015, 24, 587-594. [CrossRef]

65. Zhou, L.; Sun, L.; Xu, L.; Wan, C.; An, Y.; Ye, M. Recent Developments of Effective Catalysts for Hydrogen Storage Technology Using N-Ethylcarbazole. Catalysts 2020, 10, 648. [CrossRef]

66. Niermann, M.; Beckendorff, A.; Kaltschmitt, M.; Bonhoff, K. Liquid Organic Hydrogen Carrier (LOHC)— Assessment based on chemical and economic properties. Int. J. Hydrogen Energy 2019, 44, 6631-6654. [CrossRef]

67. Schildhauer, T.; Newson, E.; Müller, S. The Equilibrium Constant for the Methylcyclohexane-Toluene System. J. Catal. 2001, 198, 355-358. [CrossRef]

68. Sinfelt, J.H. Heterogeneous Catalysis: Some Recent Developments. Science 1977, 195, 641-646. [CrossRef] [PubMed]

69. Sinfelt, J.H. The turnover frequency of methylcyclohexane dehydrogenation to toluene on a Pt reforming catalyst. J. Mol. Catal. A Chem. 2000, 163, 123-128. [CrossRef]

70. Okada, Y.; Sasaki, E.; Watanabe, E.; Hyodo, S.; Nishijima, H. Development of dehydrogenation catalyst for hydrogen generation in organic chemical hydride method. Int. J. Hydrogen Energy 2006, 31, 1348-1356. [CrossRef]

71. Al-ShaikhAli, A.H.; Jedidi, A.; Cavallo, L.; Takanabe, K. Non-precious bimetallic catalysts for selective dehydrogenation of an organic chemical hydride system. Chem. Commun. 2015, 51, 12931-12934. [CrossRef]

72. Shukla, A.; Karmakar, S.; Biniwale, R.B. Hydrogen delivery through liquid organic hydrides: Considerations for a potential technology. Int. J. Hydrogen Energy 2012, 37, 3719-3726. [CrossRef]

73. Yan, J.; Wang, W.; Miao, L.; Wu, K.; Chen, G.; Huang, Y.; Yang, Y. Dehydrogenation of methylcyclohexane over $\mathrm{PtSn}$ supported on MgAl mixed metal oxides derived from layered double hydroxides. Int. J. Hydrogen Energy 2018, 43, 9343-9352. [CrossRef]

74. Kosaka, M.; Higo, T.; Ogo, S.; Seo, J.G.; Kado, S.; Imagawa, K.-i.; Sekine, Y. Low-temperature selective dehydrogenation of methylcyclohexane by surface protonics over Pt/anatase-TiO2 catalyst. Int. J. Hydrogen Energy 2020, 45, 738-743. [CrossRef]

75. Ninomiya, W.; Tanabe, Y.; Uehara, Y.; Sotowa, K.-I.; Sugiyama, S. Dehydrogenation of tetralin on Pd/C and $\mathrm{Te}-\mathrm{Pd} / \mathrm{C}$ catalysts in the liquid-film state under distillation conditions. Catal. Lett. 2006, 110, 191-194. [CrossRef]

76. Li, X.; Tuo, Y.; Li, P.; Duan, X.; Jiang, H.; Zhou, X. Effects of carbon support on microwave-assisted catalytic dehydrogenation of decalin. Carbon 2014, 67, 775-783. [CrossRef]

77. Jiang, N.; Rao, K.S.R.; Jin, M.-J.; Park, S.-E. Effect of hydrogen spillover in decalin dehydrogenation over supported Pt catalysts. Appl. Catal. A 2012, 425-426, 62-67. [CrossRef]

78. Suttisawat, Y.; Sakai, H.; Abe, M.; Rangsunvigit, P.; Horikoshi, S. Microwave effect in the dehydrogenation of tetralin and decalin with a fixed-bed reactor. Int. J. Hydrogen Energy 2012, 37, 3242-3250. [CrossRef]

79. Hodoshima, S.; Takaiwa, S.; Shono, A.; Satoh, K.; Saito, Y. Hydrogen storage by decalin/naphthalene pair and hydrogen supply to fuel cells by use of superheated liquid-film-type catalysis. Appl. Catal. A 2005, 283, 235-242. [CrossRef]

80. Lee, G.; Jeong, Y.; Kim, B.-G.; Han, J.S.; Jeong, H.; Na, H.B.; Jung, J.C. Hydrogen production by catalytic decalin dehydrogenation over carbon-supported platinum catalyst: Effect of catalyst preparation method. Catal. Commun. 2015, 67, 40-44. [CrossRef]

81. Martynenko, E.A.; Pimerzin, A.A.; Savinov, A.A.; Verevkin, S.P.; Pimerzin, A.A. Hydrogen Release from Decalin by Catalytic Dehydrogenation over Supported Platinum Catalysts. Top. Catal. 2020, 63, 178-186. [CrossRef]

82. Jorschick, H.; Geißelbrecht, M.; Eßl, M.; Preuster, P.; Bösmann, A.; Wasserscheid, P. Benzyltoluene/ dibenzyltoluene-based mixtures as suitable liquid organic hydrogen carrier systems for low temperature applications. Int. J. Hydrogen Energy 2020, 45, 14897-14906. [CrossRef]

83. Leinweber, A.; Müller, K. Hydrogenation of the Liquid Organic Hydrogen Carrier Compound Monobenzyl Toluene: Reaction Pathway and Kinetic Effects. Energy Technol. 2018, 6, 513-520. [CrossRef] 
84. Geißelbrecht, M.; Mrusek, S.; Müller, K.; Preuster, P.; Bösmann, A.; Wasserscheid, P. Highly efficient, low-temperature hydrogen release from perhydro-benzyltoluene using reactive distillation. Energy Environ. Sci. 2020, 13, 3119-3128. [CrossRef]

85. Eblagon, K.M.; Tsang, S.C.E. Structure-reactivity relationship in catalytic hydrogenation of heterocyclic compounds over ruthenium black; Part B: Effect of carbon substitution by heteroatom. Appl. Catal. B 2015, 163, 599-610. [CrossRef]

86. Bachmann, P.; Steinhauer, J.; Späth, F.; Düll, F.; Bauer, U.; Eschenbacher, R.; Hemauer, F.; Scheuermeyer, M.; Bösmann, A.; Büttner, M.; et al. Dehydrogenation of the liquid organic hydrogen carrier system 2-methylindole/2-methylindoline/2-methyloctahydroindole on Pt(111). J. Chem. Phys. 2019, 151, 144711. [CrossRef]

87. Cui, Y.; Kwok, S.; Bucholtz, A.; Davis, B.; Whitney, R.A.; Jessop, P.G. The effect of substitution on the utility of piperidines and octahydroindoles for reversible hydrogen storage. New J. Chem. 2008, 32, 1027-1037. [CrossRef]

88. Dong, Y.; Yang, M.; Yang, Z.; Ke, H.; Cheng, H. Catalytic hydrogenation and dehydrogenation of N-ethylindole as a new heteroaromatic liquid organic hydrogen carrier. Int. J. Hydrogen Energy 2015, 40, 10918-10922. [CrossRef]

89. Li, L.; Yang, M.; Dong, Y.; Mei, P.; Cheng, H. Hydrogen storage and release from a new promising Liquid Organic Hydrogen Storage Carrier (LOHC): 2-methylindole. Int. J. Hydrogen Energy 2016, 41, 16129-16134. [CrossRef]

90. Yang, M.; Cheng, G.; Xie, D.; Zhu, T.; Dong, Y.; Ke, H.; Cheng, H. Study of hydrogenation and dehydrogenation of 1-methylindole for reversible onboard hydrogen storage application. Int. J. Hydrogen Energy 2018, 43, 8868-8876. [CrossRef]

91. Dong, Y.; Yang, M.; Li, L.; Zhu, T.; Chen, X.; Cheng, H. Study on reversible hydrogen uptake and release of 1,2-dimethylindole as a new liquid organic hydrogen carrier. Int. J. Hydrogen Energy 2019, 44, 4919-4929. [CrossRef]

92. Forberg, D.; Schwob, T.; Zaheer, M.; Friedrich, M.; Miyajima, N.; Kempe, R. Single-catalyst high-weight $\%$ hydrogen storage in an N-heterocycle synthesized from lignin hydrogenolysis products and ammonia. Nat. Commun. 2016, 7, 13201. [CrossRef]

93. Oh, J.; Jeong, K.; Kim, T.W.; Kwon, H.; Han, J.W.; Park, J.H.; Suh, Y.-W. 2-(N-Methylbenzyl)pyridine: A Potential Liquid Organic Hydrogen Carrier with Fast H2 Release and Stable Activity in Consecutive Cycles. ChemSusChem 2018, 11, 661-665. [CrossRef]

94. Oh, J.; Kim, T.W.; Jeong, K.; Park, J.H.; Suh, Y.-W. Enhanced Activity and Stability of a Carbon-Coated Alumina-Supported Pd Catalyst in the Dehydrogenation of a Liquid Organic Hydrogen Carrier, Perhydro 2-(n-methylbenzyl)Pyridine. ChemCatChem 2018, 10, 3892-3900. [CrossRef]

95. Andersson, M.P.; Bligaard, T.; Kustov, A.; Larsen, K.E.; Greeley, J.; Johannessen, T.; Christensen, C.H.; Nørskov, J.K. Toward computational screening in heterogeneous catalysis: Pareto-optimal methanation catalysts. J. Catal. 2006, 239, 501-506. [CrossRef]

96. Bachmann, P.; Schwarz, M.; Steinhauer, J.; Späth, F.; Düll, F.; Bauer, U.; Nascimento Silva, T.; Mohr, S.; Hohner, C.; Scheuermeyer, M.; et al. Dehydrogenation of the Liquid Organic Hydrogen Carrier System Indole/Indoline/Octahydroindole on Pt(111). J. Phys. Chem. C 2018, 122, 4470-4479. [CrossRef]

97. Kim, K.; Oh, J.; Kim, T.W.; Park, J.H.; Han, J.W.; Suh, Y.-W. Different catalytic behaviors of Pd and Pt metals in decalin dehydrogenation to naphthalene. Catal. Sci. Technol. 2017, 7, 3728-3735. [CrossRef]

98. Chen, F.; Huang, Y.; Mi, C.; Wu, K.; Wang, W.; Li, W.; Yang, Y. Density functional theory study on catalytic dehydrogenation of methylcyclohexane on Pt(111). Int. J. Hydrogen Energy 2020, 45, 6727-6737. [CrossRef]

Publisher's Note: MDPI stays neutral with regard to jurisdictional claims in published maps and institutional affiliations. 